\title{
Thymic stromal lymphopoietin blocks early stages of breast carcinogenesis
}

\author{
Shadmehr Demehri, ${ }^{1,2,3}$ Trevor J. Cunningham, ${ }^{1,2,3}$ Sindhu Manivasagam, ${ }^{3}$ Kenneth H. Ngo, ${ }^{1}$ Sara Moradi Tuchayi, ${ }^{1}$ Rasika Reddy, ${ }^{2,3}$ \\ Melissa A. Meyers, ${ }^{4}$ David G. DeNardo, ${ }^{4}$ and Wayne M. Yokoyama ${ }^{3,5}$
}

'Center for Cancer Immunology and Cutaneous Biology Research Center, Department of Dermatology and MGH Cancer Center, Massachusetts Ceneral Hospital, Harvard Medical School, Boston, Massachusetts, USA. ${ }^{2}$ Division of Dermatology, ${ }^{3}$ Division of Rheumatology, ${ }^{4}$ Division of Oncology, Department of Medicine, and ${ }^{5}$ Howard Hughes Medical Institute,

Washington University School of Medicine, Saint Louis, Missouri, USA.

\begin{abstract}
Advances in the field of cancer immunology, including studies on tumor-infiltrating CD8+ cytotoxic T lymphocytes (CTLs), have led to new immunotherapeutics with proven efficacy against late-stage cancers. However, the antitumor potential of the immune system in targeting early-stage cancers remains uncertain. Here, we demonstrated that both genetic and chemical induction of thymic stromal lymphopoietin (TSLP) at a distant site leads to robust antitumor immunity against spontaneous breast carcinogenesis in mice. Breast tumors exposed to high circulating levels of TSLP were arrested at an early adenoma-like stage and were prevented from advancing to late carcinoma and metastasis. Additionally, CD4+ Th2 cells mediated the antitumor effects of TSLP, challenging the notion that Th2 cells only promote cancer. We also discovered that TSLP is expressed by the breast tumor cells themselves and acts to block breast cancer promotion. Moreover, TSLPinduced immunity also blocked early stages of pancreatic cancer development. Together, our findings demonstrate that TSLP potently induces immunity directed against early stages of breast cancer development without causing inflammation in the normal breast tissue. Moreover, our results highlight a previously unappreciated function of the immune system in controlling the early development of cancer and establish a fundamental role for TSLP and Th2 cells in tumor immunity against early-stage cancers.
\end{abstract}

\section{Introduction}

Studies of the immune response to late-stage cancers including the role of tumor-infiltrating $\mathrm{CD}^{+}$cytotoxic $\mathrm{T}$ lymphocytes (CTLs) in attacking cancer cells have led to promising new cancer immunotherapeutics with proven efficacy against melanoma and other metastatic cancers (1). However, the efficacy of immunotherapeutic approaches for the treatment of early-stage cancers is uncertain (2). This is particularly relevant to carcinomas, because these cancers frequently lack a significant antitumor immune infiltrate, especially during the early in situ phases of their development (3). The current cancer immunotherapies like immune checkpoint blockade, which rely on a preexisting CTL infiltrate in the tumor for their effects, have relatively low efficiency against the early nonimmunogenic carcinomas $(2,4)$. In order to expand the potential of cancer immunotherapy, it is essential to find pathways that lead to immune system activation against early phases of cancer development. Therefore, devising a mechanism to activate the immune system against early-stage cancers has clear therapeutic implications, both by directly blocking cancer promotion and potentiating the effects of the available cancer immunotherapeutics against the late disease.

To substantiate the possibility of immunotherapy for early cancers, we have studied thymic stromal lymphopoietin (TSLP),

Conflict of interest: The authors have declared that no conflict of interest exists. Submitted: July 13, 2015; Accepted: January 14, 2016.

Reference information: J Clin Invest. 2016;126(4):1458-1470. doi:10.1172/JCI83724. which is emerging as an important cytokine in cancer immunology (5). TSLP is an epithelium-derived cytokine that is a master regulator of allergic inflammation at barrier organs like the skin and lungs (6). We and others have previously demonstrated that epidermis-derived TSLP creates robust antitumor immunity in the skin by activating $\mathrm{CD} 4^{+} \mathrm{T}$ cells against early stages of skin cancer development (7-9). Interestingly, TSLP is expressed by mouse and human mammary gland epithelia and breast cancer cells (10), which raises the possibility that this cytokine may also play a role during the early stages of breast cancer development. Importantly, skin-derived TSLP, which can be induced by the FDA-approved topical medication calcipotriol $(11,12)$, can reach high systemic levels and activate the immune response in internal organs $(13,14)$. In addition, epidemiological data suggest that individuals with a history of allergic diseases like atopic dermatitis and asthma have a reduced risk of developing breast cancer (15-17), which may potentially be explained by elevated circulating TSLP levels in these individuals (18). Thus, an intriguing possibility with clear therapeutic implications is that systemic TSLP can induce antitumor immunity against early stages of breast cancer development.

To test the hypothesis that TSLP is active in preventing breast cancer, we studied the impact of TSLP expressed in the skin on breast tumor promotion in a murine model of spontaneous breast carcinogenesis. We demonstrate that TSLP blocks breast cancer development through activation of Th2 cells that heavily infiltrate the breast tumors. Interestingly, we discovered that TSLP released by breast tumor cells themselves functions to prevent breast 
tumor promotion. In addition, we show that induction of TSLP mounts a similar antitumor immune response against pancreatic cancer development. Collectively, these data establish a fundamental role for immune activation in combating the early stages of carcinogenesis and identify the mechanism for TSLP-mediated antitumor immunity against breast cancer.

\section{Results}

TSLP overexpression in the skin leads to $T$ cell accumulation at the site of developing breast cancer. In order to determine the impact of systemic TSLP on the early stages of breast cancer development, we studied MMTV-polyoma middle T $\left(\mathrm{PyMt}^{\mathrm{t}}{ }^{\mathrm{g}}\right)$ mice, a well-established spontaneous model of breast cancer that mimics luminal breast cancer in humans (19). We crossed this breast cancer-prone strain with mice that overexpress TSLP in their skin (K14-TSLP ${ }^{\mathrm{tg}}$ ) (20). K14-TSLPtg animals develop allergic inflammation in their skin, which mimics atopic dermatitis in humans (13). To determine the site of TSLP expression in the animals relevant to our current studies, we assessed Tslp mRNA expression in the skin and

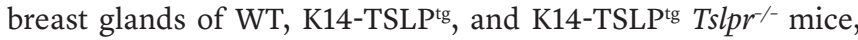
which lack TSLP-induced allergic inflammation. We detected Tslp transgene expression in the skin, but not in the breast glands (Supplemental Figure 1, A and B; supplemental material available online with this article; doi:10.1172/JCI83724DS1). Importantly, we demonstrated that Tslp overexpression in the skin led to high serum TSLP levels in K14-TSLP ${ }^{\mathrm{tg}}$ and K14-TSLP ${ }^{\mathrm{tg}} \mathrm{PyMt}^{\mathrm{tg}}$ animals (Supplemental Figure 1C). Therefore, K14-TSLP ${ }^{\mathrm{tg}}$ PyMt $^{\mathrm{tg}}$ animals could be used to investigate the impact of systemic TSLP on breast cancer development.

Analysis of the inflammatory phenotypes in K14-TSLP ${ }^{\mathrm{tg}} \mathrm{PyMt}^{\mathrm{tg}}$ animals demonstrated the development of atopic dermatitis in the skin at 10 weeks of age, which was highlighted by epidermal thickening and dermal inflammatory infiltrate including $\mathrm{CD} 4^{+} \mathrm{T}$ cells (Figure 1A and Supplemental Figure 2). We also observed an accumulation of mast cells in the dermis of K14-TSLP ${ }^{\mathrm{tg}}$ and K14-TSLP ${ }^{\mathrm{tg}}$ PyMt ${ }^{\mathrm{tg}}$ animals (Figure $1 \mathrm{~A} ; P<0.05$, Student's $t$ test) (20). Similar to K14-TSLP ${ }^{\mathrm{tg}}$ mice $(13,14), \mathrm{K}^{2} 4$-TSLP $^{\mathrm{tg}} \mathrm{PyMt}^{\mathrm{tg}}$ animals underwent atopic march and developed allergic inflammation at other barrier sites, as shown by the accumulation of $\mathrm{T}$ cell-rich inflammatory infiltrates around the lung airways (Figure 1B). Interestingly and in stark contrast to $\mathrm{K}^{14}-\mathrm{TSLP}^{\mathrm{tg}}$ mice lacking inflammation in their breast, 10-week-old K14-TSLP ${ }^{\mathrm{tg}}$ PyMt $^{\mathrm{tg}}$ mice showed a significant accumulation of $\mathrm{CD} 4^{+} \mathrm{T}$ cells surrounding their dilated mammary glands (Figure 1C). No CD4 ${ }^{+} \mathrm{T}$ cell infiltrate was detectable in early breast tumors of 10-week-old PyMt ${ }^{\mathrm{tg}}$ animals (Figure 1C). Notably, the early breast tumors developing in 10-week-old K14-TSLP ${ }^{\text {tg }}$ $\mathrm{PyMt}^{\mathrm{tg}}$ animals mostly presented as dilated mammary ducts and lacked the epithelial hyperplasia seen in PyMt ${ }^{\mathrm{tg}}$ breast ductal walls (Figure 1C). These findings suggest that TSLP stimulates a robust immune response in the breast primarily in the context of a developing tumor, which prevents the tumor from progressing into fully formed carcinoma at the primary site.

TSLP induction blocks breast carcinogenesis in the adenoma-like stage. To determine the effects of systemic TSLP on breast cancer outcomes, we monitored spontaneous breast cancer development in K14-TSLP ${ }^{\mathrm{tg}} \mathrm{PyMt}^{\mathrm{tg}}$ mice with allergic inflammation and compared it with their PyMt ${ }^{\mathrm{tg}}$ littermates over time (Figure 2).
We found that K14-TSLP ${ }^{\mathrm{tg}}$ PyMt $^{\mathrm{tg}}$ mice had a significantly longer latency to breast tumor development (Figure 2A; $P<0.001$, logrank test). In addition, the number of palpable breast tumors in each K14-TSLP ${ }^{\mathrm{tg}} \mathrm{PyMt}^{\mathrm{tg}}$ animal was significantly reduced compared with that observed in PyMt ${ }^{\mathrm{tg}}$ mice (Figure 2B; $P<0.05$, starting at 10 weeks of age, Student's $t$ test). Most notably, the lifespan of K14-TSLP ${ }^{\mathrm{tg}} \mathrm{PyMt}^{\mathrm{tg}}$ animals was not affected by their breast cancer burden after 150 days, a point at which all PyMt ${ }^{\mathrm{tg}}$ mice had succumbed to their cancer (Figure 2C; $P<0.001$, log-rank test). This stark contrast in survival rates between the 2 groups was due to the significantly smaller number of breast tumors in the K14-TSLP ${ }^{\mathrm{tg}}$ $\mathrm{PyMt}^{\mathrm{tg}}$ mice, and these tumors remained small adenoma-like precancers that lacked metastatic potential (Figure 2D and Supplemental Figure 3). Thus, the K14-TSLP ${ }^{\mathrm{tg}} \mathrm{PyMt}^{\mathrm{tg}}$ mice were greatly protected from breast cancer.

Antitumor effect of TSLP is associated with a Th2-dominant immune response at the site of developing breast tumors. To examine the possibility that TSLP-mediated breast cancer suppression was caused by underdeveloped mammary glands or by a lack of cancer initiation in K14-TSLP ${ }^{\mathrm{tg}} \mathrm{PyM}^{\mathrm{tg}}$ mice, we stained the whole mount of mammary glands and tumors from adult WT, K14TSLP $^{\mathrm{tg}}$, PyMt ${ }^{\mathrm{tg}}$, and K14-TSLP ${ }^{\mathrm{tg}}$ PyMt ${ }^{\mathrm{tg}}$ female mice with carmine stain to visualize the extent of mammary gland branching and the status of the tumors in the PyMt transgene-positive cohorts (21). Importantly, TSLP overexpression from the skin had no impact on the development of female mammary glands and their branching after puberty (Figure 3A). In addition, the presence of multiple dilated foci along the mammary ducts in K14-TSLP ${ }^{\mathrm{tg}}$ PyMt $^{\mathrm{tg}}$ breast (Figure 3A) clearly demonstrates that TSLP does not affect the initiation phase of breast carcinogenesis, but instead effectively blocks its promotion.

The suppressive effects of TSLP in blocking breast cancer promotion could possibly be mediated through the activation of antitumor immunity in the breast. To investigate this possibility, we characterized the immune environment in breast glands and tumors from age-matched WT, K14-TSLP' ${ }^{\mathrm{tg}}$, PyMt ${ }^{\mathrm{tg}}$, and K14TSLP ${ }^{\mathrm{tg}}$ PyMt $^{\mathrm{tg}}$ female mice at the time when PyMt ${ }^{\mathrm{tg}}$ mice had developed metastatic breast cancers (Figure 3). WT and K14TSLP ${ }^{\text {tg }}$ breast glands had no immune infiltrate around the mammary ducts (Figure 3B), similar to that seen at earlier time points (Figure 1). At the later stage, PyMt $\mathrm{t}^{\mathrm{tg}}$ breast cancers were composed of densely packed collections of breast cancer cells with scattered $\mathrm{T}$ cells within them; however, K14-TSLP ${ }^{\mathrm{tg}} \mathrm{PyM}^{\mathrm{tg}}$ breast tumors contained a dense $\mathrm{CD}^{+} \mathrm{T}$ cell infiltrate in close proximity to dilated mammary ducts in the tumor (Figure 3B). Quantification of the tumor-infiltrating $\mathrm{T}$ cells demonstrated that the majority of tumor-infiltrating T cells in PyMt ${ }^{\text {tg }}$ breast tumors were CD8 ${ }^{+}$CTLs, but $\mathrm{CD}^{+} \mathrm{T}$ cells were the dominant $\mathrm{T}$ cell type in $\mathrm{K}^{+} 4-\mathrm{TSLP}^{\mathrm{tg}}$ $\mathrm{PyMt}^{\mathrm{tg}}$ breast tumors (Figure $3 \mathrm{C}$ ). The accumulation of $\mathrm{CD}^{+} \mathrm{T}$ cells in K14-TSLP ${ }^{\mathrm{tg}} \mathrm{PyMt}^{\mathrm{tg}}$ breast tumors occurred in the presence of high serum TSLP levels during the development of breast cancer in these animals (Figure 3, C and D). Importantly, CD $4^{+} \mathrm{T}$ cells infiltrating the K14-TSLP ${ }^{\mathrm{tg}} \mathrm{PyMt}^{\mathrm{tg}}$ breast tumors did not express cytotoxic factors like granzyme B or FasL; however, their accumulation in K14-TSLP ${ }^{\mathrm{tg}} \mathrm{PyMt}^{\mathrm{tg}}$ breast tumors was accompanied by a significant reduction in the expression of the tumor-promoting factors IL-6 (22) and IL-8 (23) within the tumor microenvironment 

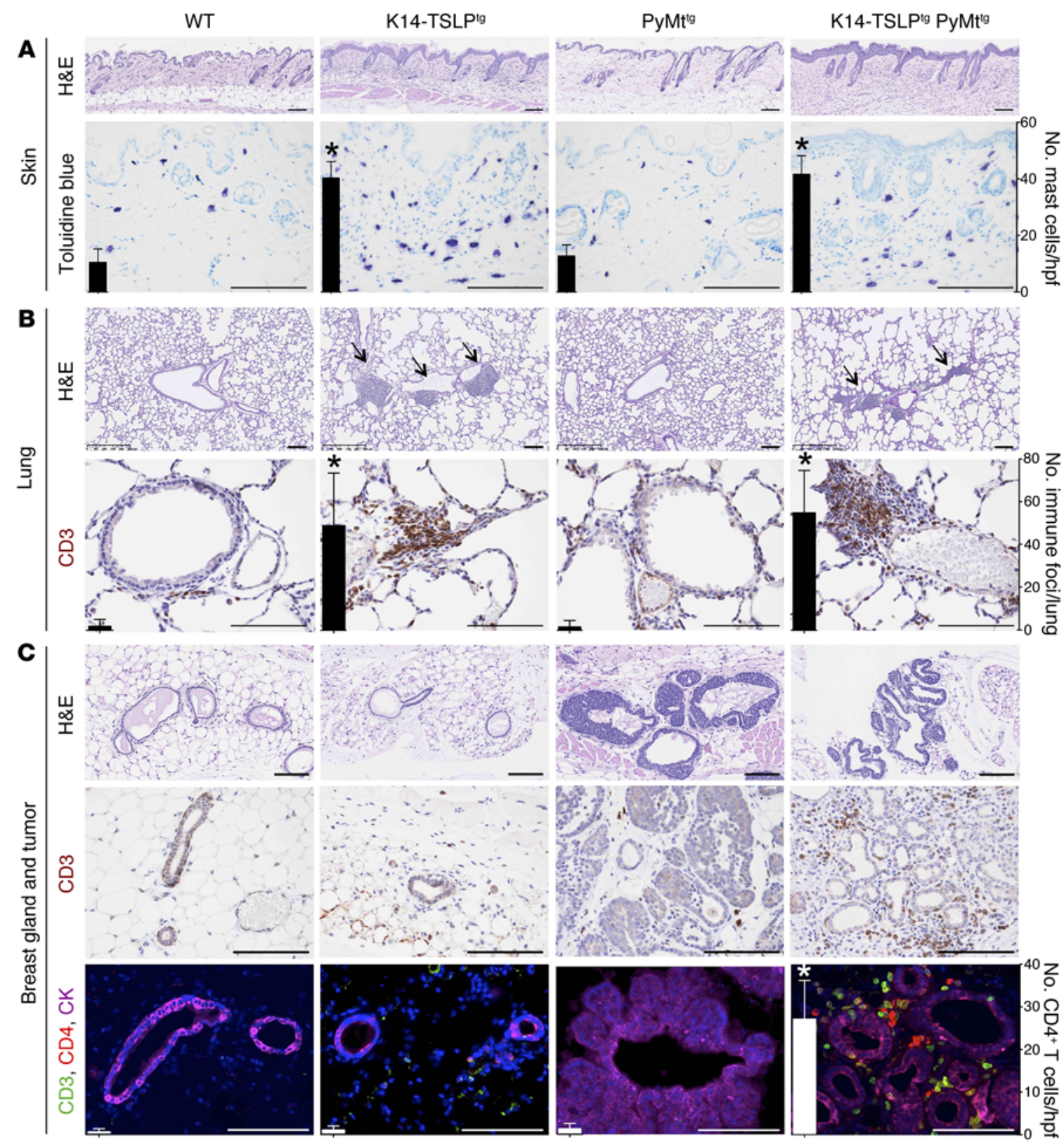

Figure 1. TSLP overexpression in the skin leads to allergic inflammation in barrier organs and induces a CD4 ${ }^{+} \mathrm{T}$ cell-mediated immune response to the developing breast tumors. (A) TSLP expression in the skin causes atopic dermatitis-like inflammation. Representative images of H\&E and toluidine blue staining (highlighting mast cells in purple) of skin from 10-week-old WT, K14-TSLP ${ }^{\mathrm{tg}}$, PyMt ${ }^{\mathrm{tg}}$, and K14-TSLPtg PyMt ${ }^{\text {tg }}$ mice are shown. The average number of mast cells in 10 random high-power fields (hpf) is shown as a bar graph at the left edge of the images ( ${ }^{*} P<0.05$ compared with WT, Student's $t$ test). (B) Elevated systemic TSLP levels caused inflammation in the lungs. Representative images of H\&E and CD3 staining (marking T cells) of lungs from 10-week-old WT, K14-TSLP ${ }^{\mathrm{tg}}$, PyMt ${ }^{\mathrm{tg}}$, and K14-TSLP ${ }^{\mathrm{tg}}$ PyMt ${ }^{\mathrm{tg}}$ mice. Arrows point to the foci of inflammation around lung airways. Higher-magnification representative images of CD3-stained lung airways are shown. Bar graphs at the left edge of the CD3-stained images show the average number of lymphocyte aggregate foci per lung section in 10 random lungs from each cohort $\left({ }^{*} P<0.05\right.$ compared with WT, Student's $t$ test). (C) TSLP induction led to accumulation of $\mathrm{CD} 4^{+} T$ cells at the site of breast cancer development and to its arrest. Representative images of H\&E, CD3 immunohistochemical, CD4, CD3, and cytokeratin (CK) immunofluorescence staining of breast glands and early tumors from 10-week-old WT, K14-TSLPtg, PyMt's, and K14-TSLPtg PyMt ${ }^{\text {tg }}$ mice. The average number of tumor-infiltrating $\mathrm{CD}^{+} \mathrm{T}$ cells in 10 random hpf is shown as a bar graph at the left edge of the immunofluorescence images ( ${ }^{*} P<0.05$ compared with WT, Student's $t$ test). Data were reproduced in 3 independent experiments. Scale bars: $100 \mu \mathrm{m}$.

(Supplemental Figure 4). Thus, systemic TSLP induction blocks breast cancer promotion and is associated with a large number of $\mathrm{CD} 4^{+} \mathrm{T}$ cells infiltrating the developing breast cancer.

Detailed analysis of the immune cells in tumor-draining lymph nodes of PyMt ${ }^{\mathrm{tg}}$ and K14-TSLP ${ }^{\mathrm{tg}} \mathrm{PyMt}^{\mathrm{tg}}$ animals showed a marked increase in $\mathrm{CD}^{+} \mathrm{T}$ and $\mathrm{CD}^{+} \mathrm{T}$ lymphocytes with effector and memory phenotypes in K14-TSLP ${ }^{\mathrm{tg}}$ PyMt $^{\mathrm{tg}}$ mice compared with that seen in PyMt ${ }^{\mathrm{tg}}$ mice (Supplemental Figure 5). Interestingly, only CD $4^{+} \mathrm{T}$ cells in K14-TSLP ${ }^{\mathrm{tg}} \mathrm{PyMt}^{\mathrm{tg}}$ lymph nodes showed increased expression of an activation marker, PD-1 (Supplemental 

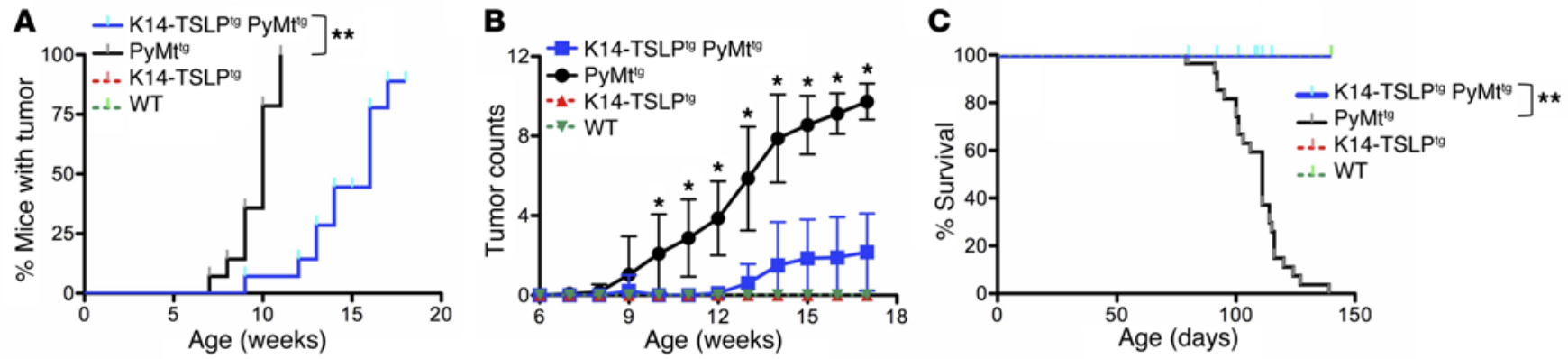

D

PyMt'9

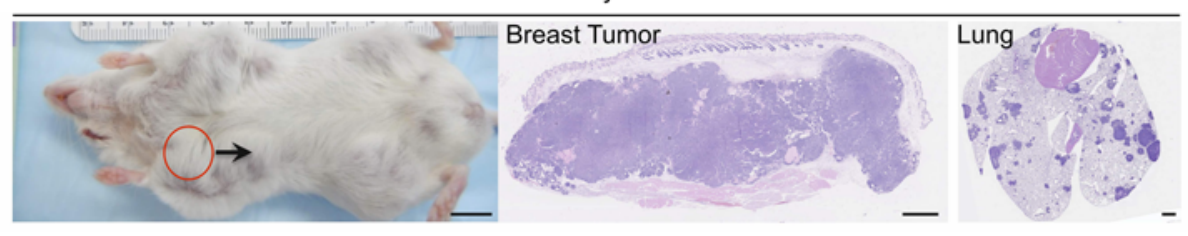

K14-TSLPtg PyMt ${ }^{\text {tg }}$

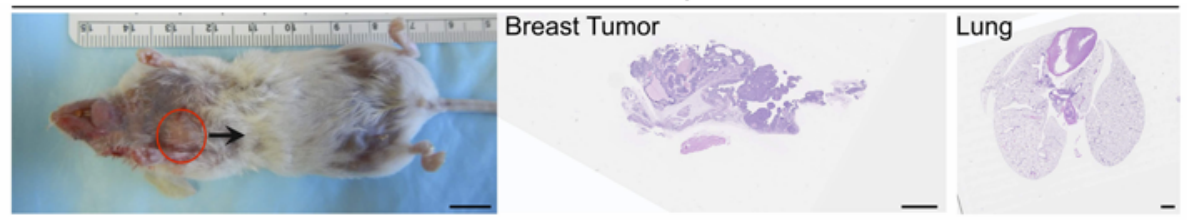

Figure 2. TSLP blocks breast cancer development. (A-C) K14-TSLP ${ }^{\text {tg }}$ PyMt ${ }^{\text {tg }}$ female mice were protected from breast cancer compared with their PyMtg counterparts. Graphs show (A) the time to tumor onset, (B) the average number of breast tumors per mouse, and (C) the animals' rate of survival ( $n \geq 14$ in each group; ${ }^{*} P<0.05$ starting at week 10 , Student's $t$ test; ${ }^{* *} P<0.001$, log-rank test). (D) K14-TSLPtg PyMttg female mice had atopic dermatitis-like skin rashes but smaller adenomatous breast tumors and no lung metastasis compared with $\mathrm{PyMt}^{\mathrm{tg}}$ mice. Representative images of $\mathrm{H} \& \mathrm{E}-\mathrm{stained}$ breast cancer and lung tissue from K14-TSLP ${ }^{\text {tg }} \mathrm{PyMt}^{\text {tg }}$ and $\mathrm{PyMt}^{\mathrm{tg}}$ female mice. Scale bars: $1 \mathrm{~cm}$ (mouse), $1 \mathrm{~mm}$ (histology).

Figure 5). $\mathrm{CD}^{+} \mathrm{T}$ cells stained for the GATA3 and FOXP3 transcription factors identified the expanded population of $\mathrm{CD}^{+}$ $\mathrm{T}$ cells in K14-TSLP ${ }^{\text {tg }}$ PyMt $^{\text {tg }}$ lymph nodes as being GATA3 ${ }^{+}$Th2 cells, while $\mathrm{FOXP}^{+}$Tregs were the dominant $\mathrm{CD} 4^{+} \mathrm{T}$ cell type in the PyMtg immune microenvironment (Supplemental Figure 5). Consistent with these findings, the expression of type 2 cytokines like Il 4 was significantly upregulated, whereas expression of type 1 cytokines such as Ifng and $T n f$ was significantly downregulated in K14-TSLP ${ }^{\text {tg }}$ PyMt ${ }^{\text {tg }}$ lymph nodes compared with that detected in PyMtg lymph nodes (Figure 4A; $P<0.05$, Student's $t$ test). TSLP induction did not induce the expression of Il33, another epitheliumderived cytokine implicated in allergic inflammation (Figure 4A, Supplemental Figure 6, and ref. 24). Importantly, immunophenotyping of the tumor-infiltrating $\mathrm{T}$ cells identified the majority of these cells as $\mathrm{CD}^{+}{ }^{+}$Th2 effector cells in K14-TSLP ${ }^{\text {tg }} \mathrm{PyMt}^{\text {tg }}$ breast tumors, because the $\mathrm{CD} 4^{+} \mathrm{T}$ cells expressed GATA3 and lacked T-bet or FOXP3 expression (Figure 4B). Despite the significant Th2 cell infiltration into the K14-TSLP ${ }^{\mathrm{tg}} \mathrm{PyMt}^{\mathrm{tg}}$ breast tumors, systemic TSLP did not result in the accumulation of mast cells or basophils within the K14-TSLP'g PyMtg tumors (Supplemental Figure 7). Finally, MHCII (I-A $\left.\mathrm{A}^{\mathrm{b}}\right)$ staining of breast tumors from K14-TSLP ${ }^{\text {tg }}$ PyMt ${ }^{\text {tg }}$ mice generated on a pure C57BL/6 background $\left(\mathrm{H} 2^{b}\right)$ showed the presence of MHC class $\mathrm{II}^{+}$antigen-presenting cells (APCs) in close contact with breast tumor cells and T cells within K14-TSLPtg PyMtg ${ }^{\text {tg }}$ breast tumors (Supplemental Figure 8).

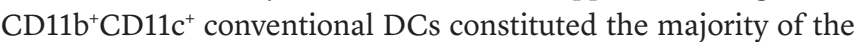
MHC class $\mathrm{II}^{+}$APCs in the breast tumors (Supplemental Figure 9 and refs. 25, 26). These findings firmly establish Th2 cells as the dominant adaptive immune cells associated with TSLP-induced antitumor immunity in the breast.

$T$ cells mediate TSLP-induced antitumor immunity in the breast. To determine whether $\mathrm{T}$ cells are required for TSLP-mediated antitumor immunity in the breast, we performed weekly Ab-based $\mathrm{CD}^{+}$and $\mathrm{CD}^{+} \mathrm{T}$ cell depletion in PyMt ${ }^{\mathrm{tg}}$ and $\mathrm{K} 14-\mathrm{TSLP}^{\mathrm{tg}} \mathrm{PyMt}^{\mathrm{tg}}$ animals starting in their second week of life, before the animals reached puberty (Figure 5). Injection of animals with anti-CD4 and anti-CD8 Abs for up to 15 weeks led to complete depletion of $\mathrm{CD}^{+}$and $\mathrm{CD} 8^{+} \mathrm{T}$ cells in the circulation (Supplemental Figure 10). Interestingly, there was complete resolution of skin inflammation in the K14-TSLP'g PyMtg animals, as shown by the normalization of hair coat, epidermal thickness, cellular density, and mast cell counts in the dermis (Figure 5A and Supplemental Figure 10). Although depletion of $\mathrm{T}$ cells did not affect the kinetics of breast cancer development in PyMt'g animals (27), sustained $\mathrm{T}$ cell depletion resulted in a clear loss of breast cancer resistance in K14-TSLP ${ }^{\text {tg }}$ PyMt ${ }^{\text {tg }}$ animals (Figure 5). K14-TSLP' PyMt ${ }^{\text {tg }}$ animals treated with anti-CD4 and anti-CD8 Abs developed multiple invasive breast cancers with tumor latency similar to that in $\mathrm{PyMtg}^{\mathrm{tg}}$ mice. Moreover, there were tumor metastases to the lungs and survival was compromised (Figure 5, B-D, and Supplemental Figure 11). To test whether $\mathrm{CD} 4^{+} \mathrm{Th} 2$ cells specifically mediated the antitumor effects of TSLP in the K14-TSLP ${ }^{\text {tg }}$ PyMt ${ }^{\text {tg }}$ breast, we attempted to deplete only $\mathrm{CD} 4^{+}$or $\mathrm{CD} 8^{+} \mathrm{T}$ cells in K14-TSLPtg $\mathrm{PyMt}^{\mathrm{tg}}$ animals following the same protocol as above. Although 
A
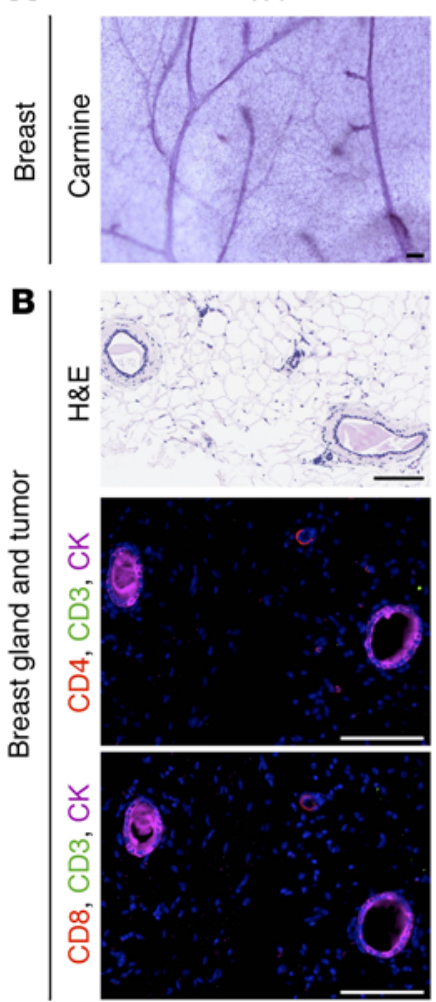

K14-TSLPtg
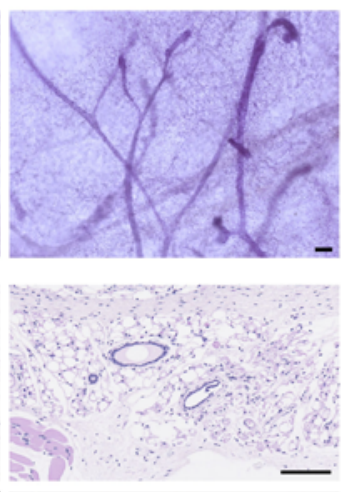
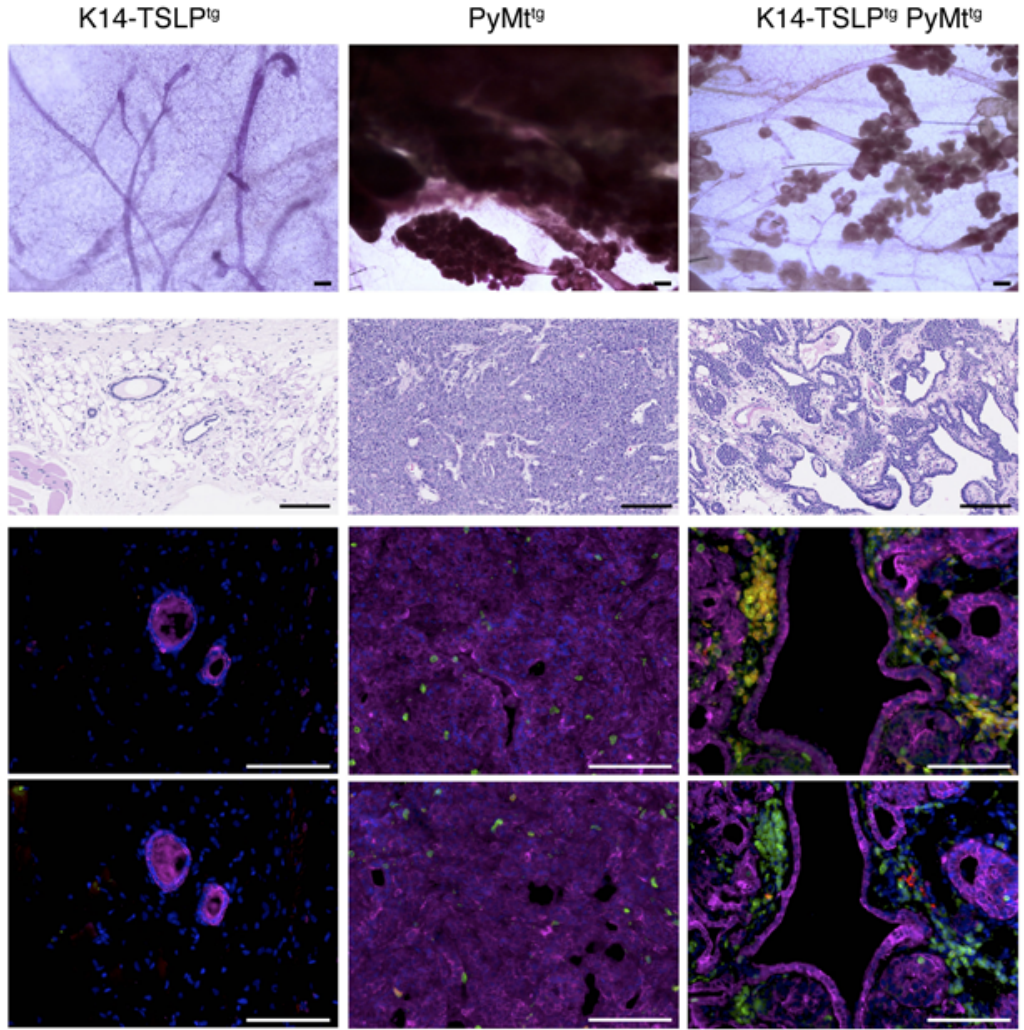

C $\square \mathrm{CD4^{+ } \mathrm { T }}$ $\square \mathrm{CD} 8^{+} \mathrm{T}$
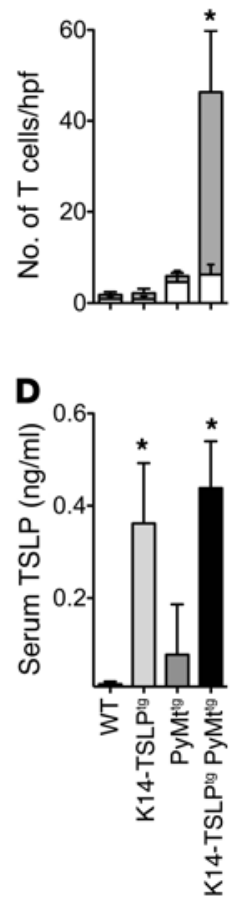

Figure 3. TSLP-induced breast cancer suppression is associated with accumulation of CD4 ${ }^{+} \mathrm{T}$ cells around the arrested breast tumor foci. (A) Breast gland development in K14-TSLPtg PyMt ${ }^{\text {tg }}$ female mice was intact, but the breast cancer promotion phase was inhibited in these animals. Representative images of carmine-stained (mammary ducts in red) breast glands and tumors from age-matched WT, K14-TSLPtg, PyMt ${ }^{\text {tg }}$, and K14-TSLPtg PyMt ${ }^{\text {tg }}$ female mice when PyMt ${ }^{\text {tg }}$ animals had developed palpable tumors. (B) Endpoint histological analysis revealed CD4+ $\mathrm{T}$ cell infiltrate surrounding dilated mammary ducts in K14-TSLP ${ }^{\text {tg }} \mathrm{PyMt}^{\mathrm{tg}}$ female mice. Representative images show H\&E, CD4/CD3/CK, and CD8/CD3/CK immunofluorecence staining of adjacent sections of breast glands and tumors. Note that the tissues were from age-matched WT, K14-TSLPtg, PyMt ${ }^{\text {tg }}$, and K14-TSLP ${ }^{\text {tg }}$ PyMt ${ }^{\text {tg }}$ female mice when the PyMt $^{\text {tg }}$ animals had developed terminal metastatic breast cancers. (C) The majority of T cells in K14-TSLP ${ }^{\text {tg }}$ PyMt ${ }^{\text {tg }}$ tumors were CD4+ T cells. Bar graphs show the average number of tumor-infiltrating $C D 4^{+}$and $C D 8^{+} T$ cells in 10 random hpf within the glands and tumors of WT, K14-TSLPts, PyMt ${ }^{\text {tg }}$, and K14-TSLP ${ }^{\text {tg }}$ PyMt ${ }^{\text {tg }}$ mice $\left({ }^{*} P<0.05\right.$ compared with PyMt ${ }^{\text {tg }}$, Student's $t$ test). (D) At the terminal stage of cancer in PyMt ${ }^{\text {tg }}$ mice, circulating TSLP levels rose in PyMt ${ }^{\text {tg }}$ mice, but remained significantly higher in K14-TSLPts and K14-TSLPtg PyMtg animals. Bar graph shows the serum TSLP levels in WT, K14-TSLPts, PyMt ${ }^{\text {tg }}$, and K14-TSLPtg PyMt ${ }^{\text {tg }}$ female mice when the PyMt ${ }^{\text {tg }}$ animals had reached the metastatic breast cancer endpoint ( $n=4$ per group; ${ }^{*} P<0.05$ compared with WT, Student's $t$ test). Data were reproduced in 3 independent experiments. Scale bars: $100 \mu \mathrm{m}$.

anti-CD8 Ab depletion alone led to an effective depletion of CD8 ${ }^{+}$ $\mathrm{T}$ cells in K14-TSLPtg PyMt's blood, anti-CD4 Ab alone failed to deplete $\mathrm{CD} 4^{+} \mathrm{T}$ cells, probably due to the TSLP stimulatory pressure on these cells (Supplemental Figure 12). Notably, and despite the effective $\mathrm{CD} 8^{+} \mathrm{T}$ cell depletion, anti-CD8 Abs failed to alter the allergic skin inflammation in the K14-TSLP ${ }^{\text {tg }}$ PyMt ${ }^{\text {tg }}$ animals (Supplemental Figure 12, A and B). These findings demonstrate that $\mathrm{T}$ cells play an essential role in mediating the antitumor immune response mounted by TSLP in the breast and that $\mathrm{CD} 4^{+} \mathrm{Th} 2$ cells are the likely $\mathrm{T}$ cell type required for this effect.

TSLP-stimulated Th2 cells are responsible for blocking breast cancer promotion. We established the tumor-protective effects of systemic TSLP against breast cancer using mice on a tumor-prone FVB genetic background. In order to show similar effects in a different genetic background and provide the foundation for a more detailed study of the role of $\mathrm{CD} 4^{+} \mathrm{T}$ cells in TSLP-mediated tumor immunity, we studied K14-TSLP ${ }^{\text {tg }}$ PyMt ${ }^{\text {tg }}$ and K14-TSLP ${ }^{\text {tg }}$ PyMt $^{\text {tg }}$ $\mathrm{Tslpr}^{\wedge}$ animals generated on a pure C57BL/6 genetic background (Supplemental Figure 13). Similar to the corresponding mice on the
FVB genetic background, K14-TSLP ${ }^{\text {tg }}$ PyMt ${ }^{\text {tg }}$ mice on the C57BL/6 genetic background were resistant to breast cancer development, and this resistance was completely reversed in K14-TSLP ${ }^{\text {tg }} \mathrm{PyM}^{\mathrm{tg}}$ $\mathrm{Tslpr}^{\circ-}$ mice, which were prone to developing breast cancer to a degree similar to that seen in PyMt ${ }^{\mathrm{tg}}$ animals (Supplemental Figure 13). To establish an experimental system that allowed for a predictable tumor promotion time frame and controlled outcome measurements, we orthotopically implanted primary breast tumor cells from $\mathrm{PyMt}^{\mathrm{tg}}$ mice into the inguinal mammary fat pads of WT and K14-TSLP't recipients (Supplemental Figure 14). Breast tumors grew significantly larger in WT animals compared with that observed in their K14-TSLP ${ }^{\text {tg }}$ counterparts, in which the tumors were mostly arrested as small nodules that had dilated breast ducts within them (Supplemental Figure 14; $P<0.05$, Student's $t$ test). This result confirms that TSLP blocks the promotion of an implanted primary breast tumor, which is identical to its effects on a spontaneously forming breast tumor.

Next, we investigated the role of $\mathrm{CD} 4^{+} \mathrm{T}$ cells in TSLP-mediated immunity against breast cancer (Figure 6A). Primary breast 
A

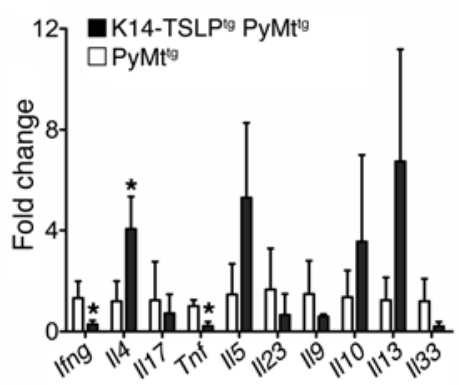

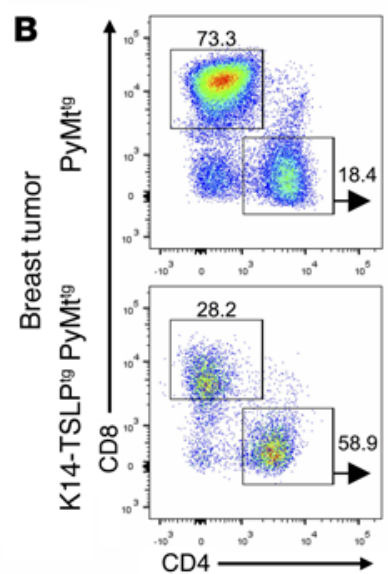

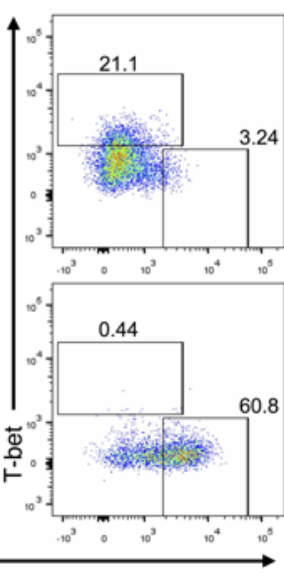

- K14-TSLP'9 PyMt's $\square \mathrm{PyMt}^{\mathrm{t} 9}$

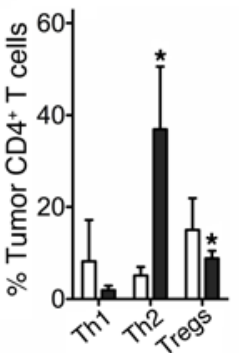

Figure 4. TSLP induces the accumulation of $\mathrm{CD4}^{+} \mathrm{T}$ cells and their polarization to Th2 cells in breast tumors and their draining lymph nodes. (A) Cytokine profiling of the tumor-draining lymph nodes revealed that the Th2-polarized cytokine milieu dominated in K14-TSLP ${ }^{\text {tg }}$ PyMt ${ }^{\text {tg }}$ animals. Bar graphs show the relative mRNA expression of several Th1- and Th2-related cytokines versus Gapdh in K14-TSLPts PyMt's tumor-draining lymph nodes compared with $\mathrm{PyMt}^{\mathrm{tg}}$ tumor-draining lymph nodes ( $n=4$ per group; ${ }^{*} P<0.05$ compared with PyMt ${ }^{\mathrm{t} g}$, Student's $t$ test). (B) Th2 cells formed the dominant type of T cells infiltrating the K14-TSLPtg PyMt ${ }^{\text {tg }}$ breast tumors. Representative flow cytometric plots show the percentage of CD4 ${ }^{+}$and $C D 8^{+} \mathrm{T}$ cells in PyMt ${ }^{\text {tg }}$ and K14-TSLP ${ }^{\text {tg }}$ PyMt ${ }^{\text {tg }}$ breast tumors. T-bet, GATA3, and FOXP3 transcription factor staining delineated the characteristics of the tumor-infiltrating CD4 T cells in PyMt ${ }^{\text {tg }}$ and K14-TSLPtg PyMt ${ }^{\text {tg }}$ animals. Flow cytometric data were reproduced in 6 independent experiments. Data were collected when PyMt ${ }^{\text {tg }}$ animals had reached the metastatic breast cancer endpoint. Numbers in the flow cytometric plots represent the percentage of the plotted cell population. Bar graph demonstrates the percentage of Th1 and Th2 cells and Tregs within the PyMt ${ }^{\text {tg }}$ and K14-TSLP ${ }^{\text {tg }}$ PyMt $^{\text {tg }}$ breast tumors ( $n \geq 4$ per group; ${ }^{*} P<0.05$ compared with PyMt ${ }^{\text {tg }}$, Student's $t$ test).

tumors were isolated from PyMt ${ }^{\mathrm{tg}} \mathrm{Tslpr}^{-/}$animals, which lack the TSLP receptor on all their cells, including the immune cells that might have been left behind, even after $\mathrm{CD} 45^{+}$cell depletion of the tumor. These tumors were transferred to K14-TSLPtg $\mathrm{Ts}^{\mathrm{p}} \mathrm{pr}^{-1}$ female mice, which, prior to tumor implantation, had received $\mathrm{Ts}_{\mathrm{pr}} \mathrm{p}^{--}$or congenically marked $\mathrm{WT} \mathrm{CD}^{+} \mathrm{T}$ cells from naive mice (Figure 6A). Interestingly, the breast tumors that formed in inguinal mammary fat pads of the recipient K14-TSLPtg $\mathrm{Ts}^{\mathrm{p}} \mathrm{pr}^{-1}$ mice were significantly smaller in the mice receiving WT CD $4^{+}$ $\mathrm{T}$ cells than in those receiving $\mathrm{Tslpr}^{-/} \mathrm{CD} 4^{+} \mathrm{T}$ cells (Figure 6B; $P<0.05$, Student's $t$ test). A similar result was obtained when the tumor cells were injected into thoracic mammary fat pads (Supplemental Figure 15). Remarkably, the majority of the tumorinfiltrating WT CD4 ${ }^{+} \mathrm{T}$ cells that rendered recipient K14-TSLPtg Tslpr/- mice resistant to breast tumors became GATA3 ${ }^{+}$Th 2 cells and showed a higher degree of proliferation compared with the Tslpr ${ }^{-/} \mathrm{CD}^{+} \mathrm{T}$ cells present in the tumor (Figure 6C). Collectively, these data provide strong evidence that Th2 cells stimulated by TSLP are at the heart of the antitumor immunity against breast cancer development, while also indicating that the breast tumor cells themselves are not responding to TSLP.

Topical induction of TSLP blocks breast tumor growth in a Th2 cell-dependent manner. We hypothesized that the induction of TSLP at the time of breast cancer development provides the potential to be an effective immunotherapeutic approach for breast cancer treatment. To test this hypothesis, we used an FDA-approved topical medication, calcipotriol, which is a known inducer of TSLP in the skin (11). We administered $20 \mathrm{nmol}$ calcipotriol or EtOH carrier onto the ears of age-matched WT and Tslpr-/- female mice every 3 days, starting immediately before adoptive transfer of congenically marked WT $\mathrm{CD}^{+} \mathrm{T}$ cells and implantation of primary
$\mathrm{PyMt}^{\mathrm{tg}} \mathrm{Ts} \mathrm{pr} \mathrm{r}^{-/}$breast tumor cells into their right inguinal mammary fat pad (Figure 7A). Topical application of calcipotriol onto the animals' ears led to a significant increase in circulating TSLP levels (Figure 7B, $P<0.05$, Student's $t$ test). WT animals that received calcipotriol developed significantly smaller tumors compared with EtOH-treated WT controls (Figure 7, C and D, $P<0.05$, Student's $t$ test). Interestingly, $\mathrm{Ts}_{\mathrm{pr}}{ }^{--}$mice treated with EtOH developed significantly larger tumors than did EtOH-treated WT controls (Figure 7, $\mathrm{C}$ and $\mathrm{D}, P<0.05$, Student's $t$ test). This finding demonstrates that endogenous TSLP released by the breast cancer cells (Supplemental Figure 16) acts to suppress breast cancer growth (Figure 7, C and D). s $\mathrm{pr}^{-1}$ mice treated with calcipotriol showed tumor growth kinetics similar to that seen in EtOH-treated Ts $\mathrm{pr}^{-/-}$mice, demonstrating that the calcipotriol effect on breast cancer suppression is mediated through TSLP (Figure 7, C and D). Importantly, Tslpr-1mice that received both $\mathrm{WT} \mathrm{CD4} 4^{+} \mathrm{T}$ cells and calcipotriol gained a robust resistance to breast tumor growth, highlighting the observation that $\mathrm{CD}^{+} \mathrm{T}$ cells directly responded to TSLP signal and mounted an antitumor immune response in the breast (Figure 7, C and $\mathrm{D}, P<0.05$, Student's $t$ test).

To further investigate the nature of the $\mathrm{CD} 4^{+} \mathrm{T}$ cells responsible for antitumor immunity in the breast in response to topical calcipotriol treatment, we determined their transcription factor expression pattern. As shown in a genetic model of TSLP induction, WT mice treated with calcipotriol showed expansion of GATA3 $^{+}$Th2 cells in their growth-arrested tumors (Figure 7E). Notably, WT CD $4^{+}$T cells that were transferred into calcipotrioltreated $\mathrm{Tslpr}^{-1}$ mice and responsible for mounting the TSLPinduced antitumor immune response became GATA3 ${ }^{+}$Th 2 cells (Figure 7E). Evaluation of ears, back skin, and lungs in the calcipotriol-treated animals showed localized inflammation in the 
A

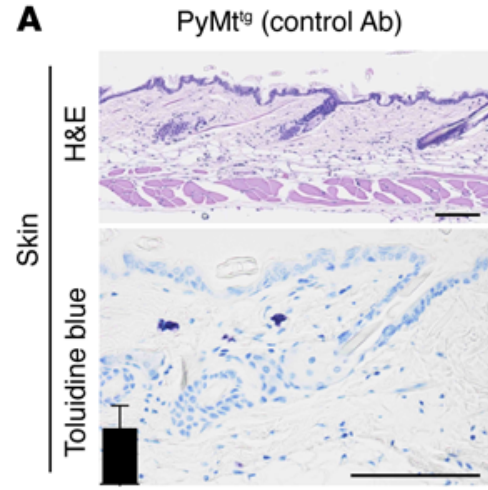

K14-TSLP ${ }^{\text {tg }}$ PyMt $^{\text {tg }}$ (control Ab)

PyMt $^{\text {tg }}(C D 4 / 8 \mathrm{Ab})$

K14-TSLP ${ }^{\text {tg }}$ PyMt'g $^{\text {(CD4/8 Ab) }}$
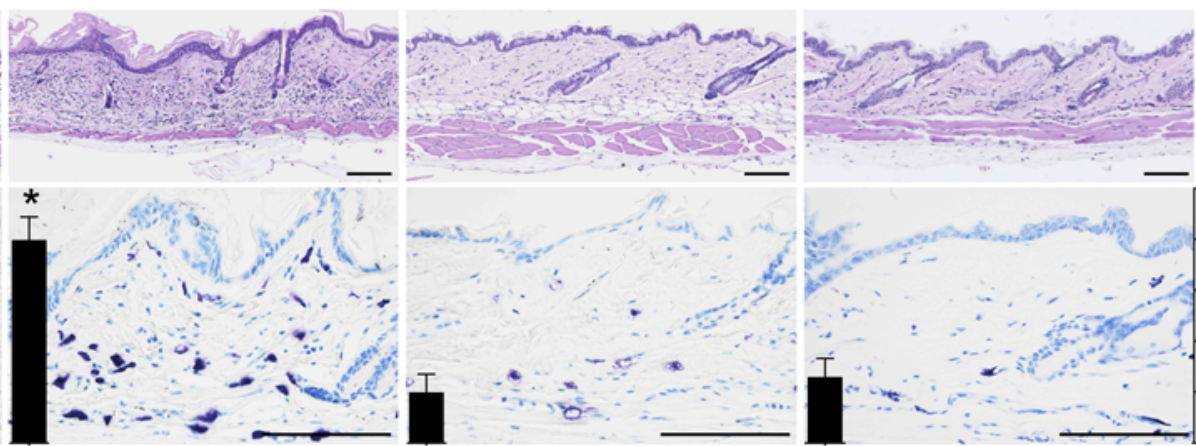

B
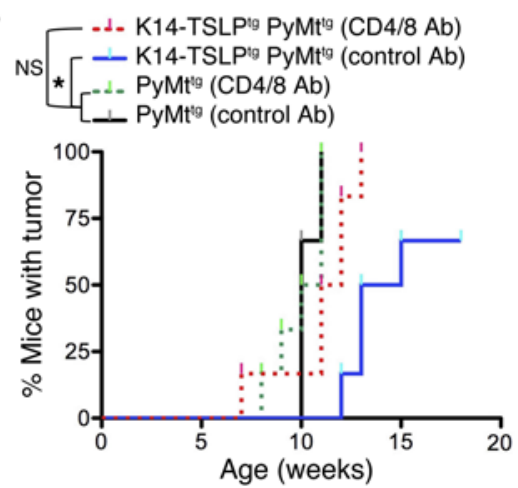

C

-4- K14-TSLP ${ }^{t 9} \mathrm{PyMt}^{+19}$ (CD4/8 Ab)

- K14-TSLP'9 PyMt'g (control Ab)

-7- PyMt $^{\mathrm{g}}$ (CD4/8 Ab)

$\rightarrow$ PyMt $^{\circ 9}$ (control $\mathrm{Ab}$ )

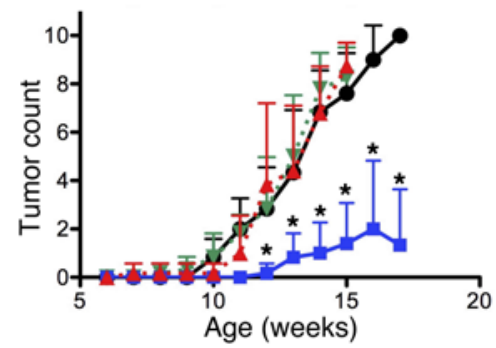

D
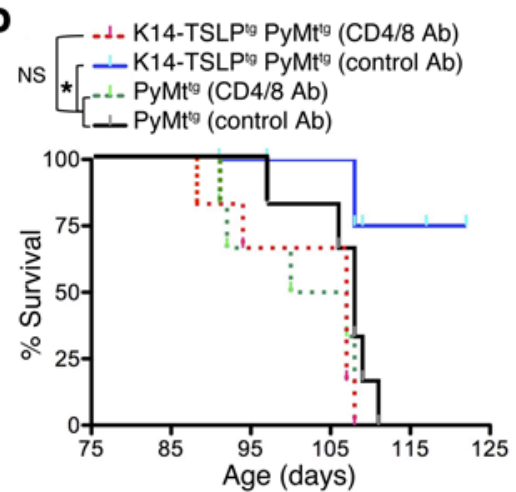

Figure 5. T cells are required for TSLP-induced antitumor immunity in the breast. (A) CD4+ and CD8 ${ }^{+} \mathrm{T}$ cell depletion starting in the second week of life abrogated the atopic dermatitis-like skin inflammation in K14-TSLPtg PyMt ${ }^{\text {tg }}$ mice. Representative images are shown of H\&E- and toluidine blue-stained skin from adult PyMt ${ }^{\text {tg }}$ and K14-TSLPts PyMt ${ }^{\text {tg }}$ mice. The animals were analyzed when the control Ab-treated PyMt ${ }^{\text {tg }}$ mice had developed terminal disease. The average number of mast cells in 10 random hpf is shown as a bar graph in the left edge of the images $\left({ }^{*} P<0.05\right.$ compared with PyMt ${ }^{\text {tg }}$ treated with control Ab, Student's $t$ test). Scale bars: $100 \mu \mathrm{m}$. (B-D) K14-TSLPtg PyMtts female mice treated with anti-CD4 and anti-CD8 Abs (CD4/8 Ab) lost their resistance against breast cancer development. Graphs show (B) the time to tumor onset, (C) the average number of breast tumors per mouse, and (D) the survival percentage for anti-CD4-, anti-CD8-, and control Ab-treated PyMt ${ }^{\text {tg }}$ and $\mathrm{K} 14-\mathrm{TSLP}{ }^{\mathrm{tg}} \mathrm{PyMt} \mathrm{t}^{\mathrm{tg}}$ mice ( $n=6$ in each group). ${ }^{*} P<0.05$, log-rank test (B and D); ${ }^{*} P<0.05$ starting at week 12 compared with PyMt ${ }^{\text {tg }}$ treated with control Ab, Student's $t$ test (C).

ears, but no sign of systemic allergic inflammation at the barrier organs in response to the short-term induction of TSLP through topical calcipotriol treatment (Supplemental Figure 17). Together, these findings demonstrate the tumor-suppressive effects of endogenous TSLP expressed by a developing breast cancer and substantiate the potential of TSLP induction to yield an effective immunotherapeutic for breast cancer treatment with minimal systemic side effects.

TSLP induction blocks tumor growth in late-stage breast cancer. We have demonstrated that systemic induction of TSLP and local TSLP expression by breast cancer cells act to suppress breast cancer development. In contrast to our findings, previous studies showed that endogenous TSLP released from breast cancer cell lines is protumorigenic $(10,28)$. To test the effects of systemic TSLP induction on a breast cancer cell line, we generated a cell line from PyMt ${ }^{\mathrm{tg}}$ breast tumors (Supplemental Figure 18A). Consistent with previous findings $(10,28)$, WT animals injected with the $\mathrm{PyMt}^{\mathrm{tg}}$ tumor cell line developed significantly larger tumors compared with $\mathrm{Tslpr}^{-/}$recipients (Supplemental Figure $18 ; P<0.05$, Student's $t$ test). The reason for the opposite effect of endogenous TSLP on tumor cell lines is unclear, but it should be noted that breast cancer cell line-derived tumors are poorly differ- entiated and have lost epithelial characteristics such as cytokeratin expression, similar to a late-stage metastatic cancer (Supplemental Figure 19). Nonetheless, we found that tumor cell line growth was still suppressed in K14-TSLP ${ }^{\text {tg }}$ animals (Supplemental Figure $18 ; P<0.05$ compared with WT, Student's $t$ test). Notably, $\mathrm{CD} 4^{+} \mathrm{T}$ cells, which were largely GATA3 ${ }^{+}$Th2 polarized, constituted the majority of tumor-infiltrating lymphocytes in K14-TSLP ${ }^{\mathrm{tg}}$ mice compared with WT and Tslpr ${ }^{--}$animals (Supplemental Figure 18; $P<0.05$, Student's $t$ test). Thus, TSLP expressed locally by breast tumor cells can be coopted by tumor-derived cell lines to promote the growth of the breast tumor cells, but TSLP induction can still block their growth by recruiting Th2 cells to the tumor, consistent with our findings of the tumor-suppressive effect of TSLP on developing primary tumors.

TSLP induction blocks pancreatic tumor growth. In order to determine the extent of the TSLP tumor-suppressive effects in blocking early cancer development, we examined the role of TSLP in pancreatic cancer, which is a prime example of a cancer with minimal baseline immunity (3). A previous study has suggested that endogenous TSLP released by pancreatic cancer-associated fibroblasts is protumorigenic in metastatic pancreatic cancer (29). Therefore, elucidating the role of TSLP in early-stage pancreatic 
A

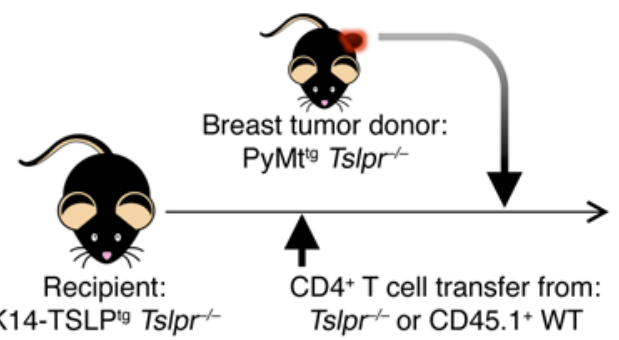

B

B Breast tumor donor: PyMt'9 Ts/pr

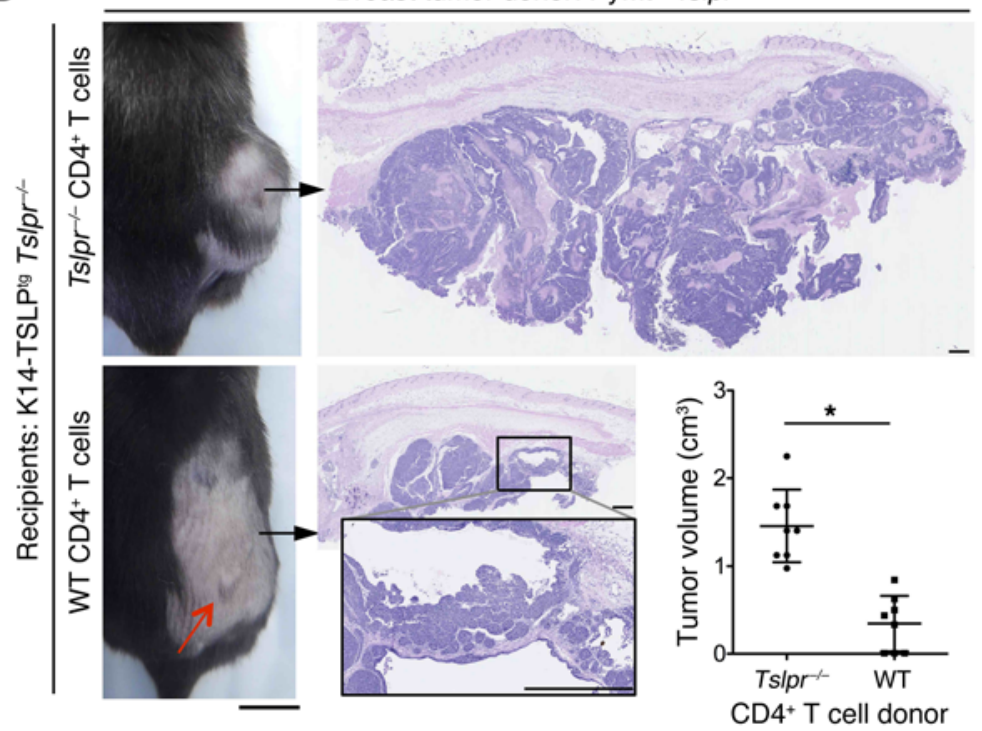

Figure 6. TSLP blocks breast cancer promotion through stimulation of Th2 cells. (A) Schematic diagram depicting the experimental paradigm used to test the role of $\mathrm{CD}^{+} T$ cells in TSLP-mediated immunity against breast cancer. Six- to eight-

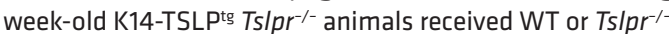
$\mathrm{CD}^{+} \mathrm{T}$ cells and were implanted 2 days later with PyMt's $\mathrm{Ts}_{\mathrm{Ipr}}{ }^{-1-}$ primary breast tumors. WT CD4 ${ }^{+} \mathrm{T}$ cells were congenically marked (CD45.1 $1^{+}$). (B) WT CD4 ${ }^{+} T$ cells were sufficient to receive TSLP signal and mount an antitumor immune response in the breast. Representative images are shown of K14-TSLPtg $\mathrm{Ts}_{\mathrm{S}} \mathrm{pr}^{-1-}$ mice with their implanted tumors. Red arrow points to a small tumor in the K14-TSLPts $\mathrm{Ts}_{\mathrm{Pr}} \mathrm{r}^{-1}$ animal injected with WT CD4+ T cells. Shown are H\&E-stained tumor sections isolated from K14-TSLPtg Ts/pr-1- animals that received WT or $T s / p r^{-1-} \mathrm{CD} 4^{+} \mathrm{T}$ cells. Inset highlights an area of the tumor that shows reversion to a dilated gland structure in a small tumor that formed in the K14-TSLPtg $\mathrm{Ts}_{\mathrm{s}} \mathrm{pr} \mathrm{r}^{-}$- mouse injected with WT $\mathrm{CD}^{+} \mathrm{T}$ cells. Scatter plot shows the average volume of the breast tumors forming in each K14-TSLPtg $\mathrm{Ts}^{\mathrm{p}} \mathrm{pr}-{ }^{-/}$mouse that received WT or Ts/pr $r^{-1-} \mathrm{CD} 4^{+} \mathrm{T}$ cells at the time point when the tumors of the $\mathrm{Ts}_{\mathrm{s}} \mathrm{pr}^{-1-} \mathrm{T}$ cell-injected animals had reached their terminal volume ( $n=8$ in each group; ${ }^{*} P<0.05$, Student's $t$ test). Scale bars: $1 \mathrm{~cm}$ (mouse), $500 \mu \mathrm{m}$ (histology). (C) WT $\mathrm{CD}^{+} \mathrm{T}$ cells isolated from growth-arrested breast tumors of K14-TSLPtg Ts/pr/- mice were polarized to Th2 cells and showed increased proliferation. Representative flow cytometric plots show the FOXP3 and GATA3 expression status of tumorinfiltrating $\mathrm{CD}^{+} \mathrm{T}$ cells in K14-TSLPtg $\mathrm{Ts}_{\mathrm{N}} \mathrm{rr}^{-1-}$ mice that received WT or Ts/pr $r^{--}$CD4 $4^{+}$T cells. Congenically marked (CD45.1+) WT $\mathrm{CD}^{+} \mathrm{T}$ cells are highlighted in red. Numbers in the flow plots represent the percentage of cells within each box. Histograms show the percentage of $\mathrm{Ki} 67^{+} \mathrm{CD} 4^{+} \mathrm{T}$ cells.

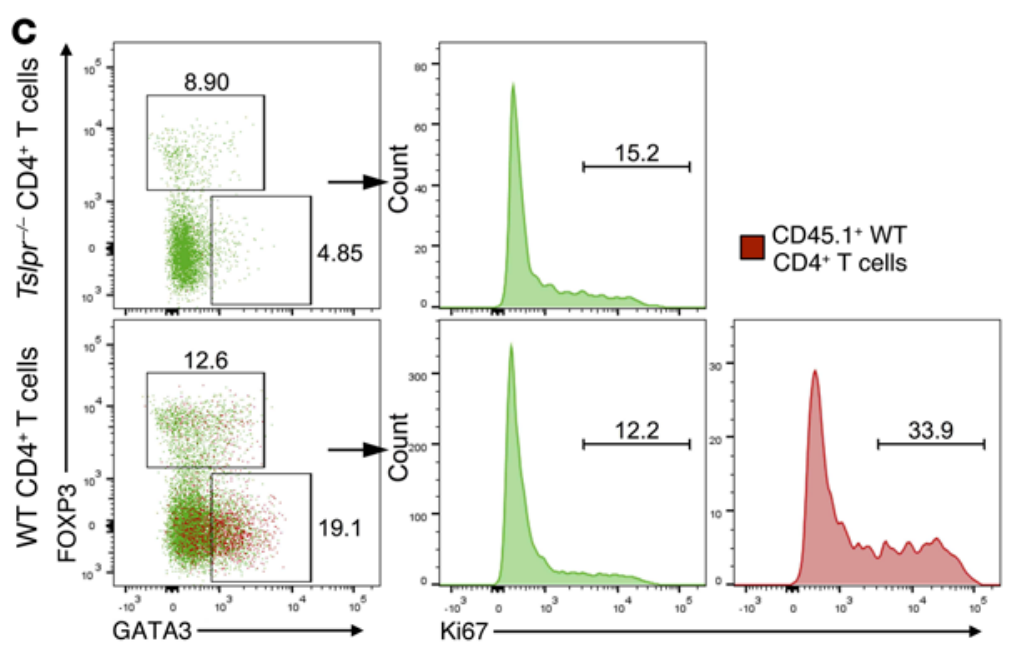

cancer has major implications for our understanding of TSLP's function in cancer. To test the effect of TSLP induction on pancreatic cancer development, we isolated spontaneous pancreatic tumors from $\mathrm{P} 48^{+/ \text {Cre }}$ LSL-KRAS ${ }^{\mathrm{G} 12 \mathrm{D}} p 53^{f /+}$ animals (30). These primary tumors were transferred into WT and K14-TSLP ${ }^{\text {tg }}$ mice to monitor their growth in the presence of systemic TSLP. Interestingly, pancreatic tumors formed in K14-TSLP ${ }^{\mathrm{tg}}$ mice were significantly smaller than those formed in WT mice (Figure 8, A and $\mathrm{B} ; \mathrm{P}<0.05$, Student's $t$ test). Importantly, there was a significant increase in the number of GATA $3^{+}$Th2 cells infiltrating K14-TSLPtg tumors compared with that seen in their WT counterparts (Figure $8, \mathrm{C}$ and $\mathrm{D} ; P<0.05$, Student's $t$ test). These findings demonstrate that systemic TSLP induction against primary pancreatic tumors leads to their growth suppression, accompanied by a significant accumulation of Th2 cells within the tumor microenvironment.

\section{Discussion}

The main impact of this report is the demonstration that an antitumor immune response can be effectively induced against early stages of cancer development. The ability to activate the immune system to attack a developing cancer highlights a novel aspect of cancer immunology with great potential to produce robust and durable treatments against cancer. This approach can yield cancer immunopreventive measures that will eliminate carcinoma in situ, 
A

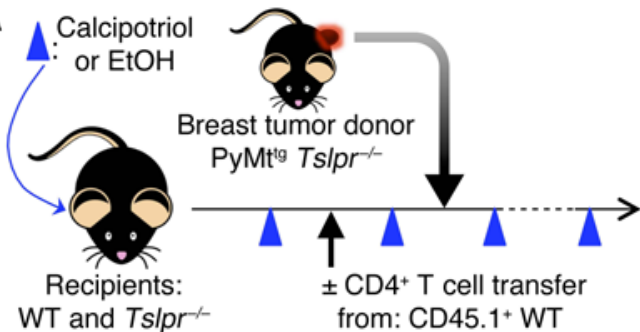

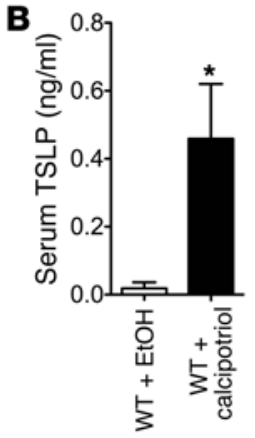

C

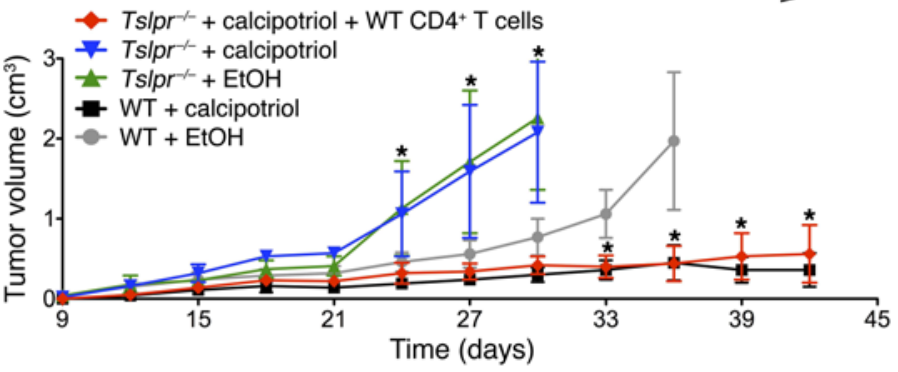

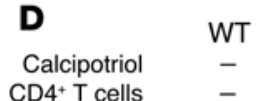
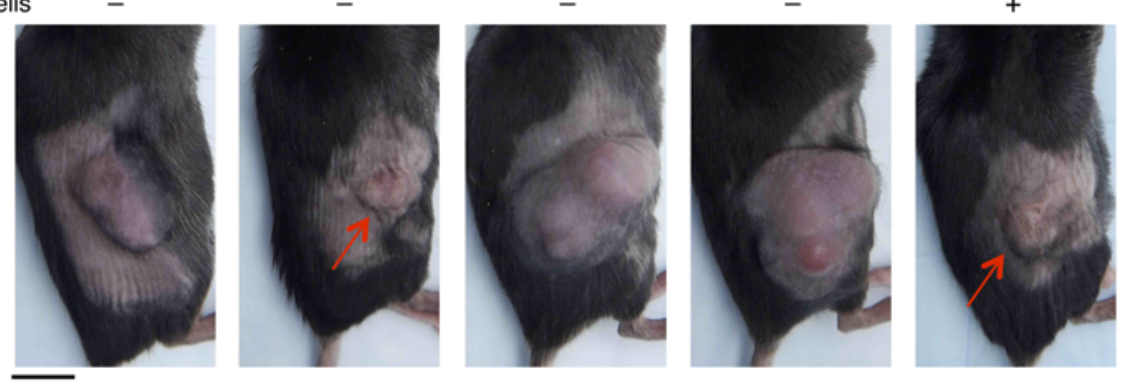

E
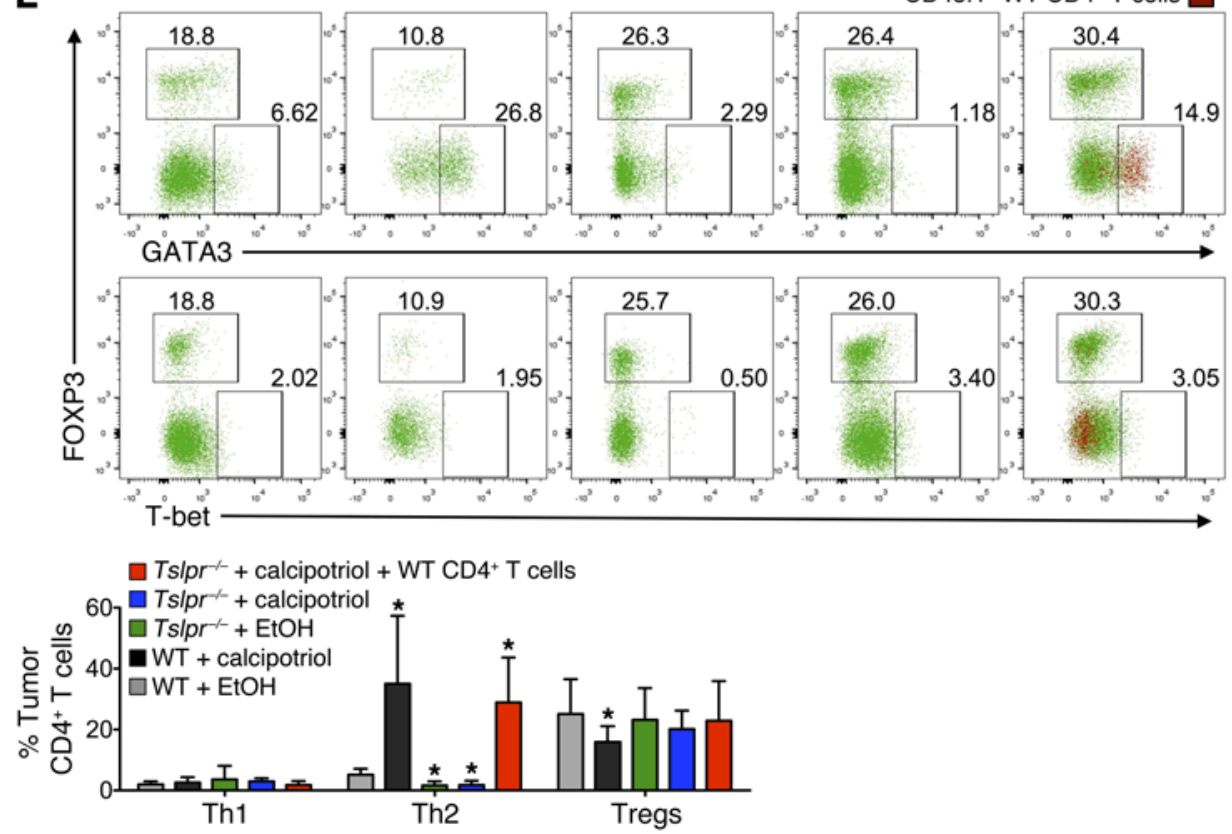

Figure 7. Topical TSLP induction blocks breast cancer development. (A) Schematic diagram outlining the experimental design used to test the efficacy of topical calcipotriol treatment in blocking breast cancer development. Six- to eight-weekold WT and $\mathrm{Ts}_{\mathrm{IPr}} \mathrm{F}^{--}$animals were used as tumor recipients. The animals were treated with $20 \mathrm{nmol}$ calcipotriol or $\mathrm{EtOH}$ on their ears every 3 days, starting before adoptive T cell transfer (in a subgroup of $\mathrm{Ts} \mathrm{pr}^{-1-}$ animals) and $\mathrm{PyMt}{ }^{\text {tg }} \mathrm{Ts}^{\mathrm{p}} \mathrm{pr}^{-1-} \mathrm{pri}^{-}$ mary breast tumor implantation. (B) Topical calcipotriol treatment on ears led to elevated TSLP levels in the circulation. Bar graph shows the average levels of TSLP in the serum of WT mice treated with calcipotriol or EtOH ( ${ }^{*} P<0.05$, Student's $t$ test). (C and D) TSLP induction by calcipotriol blocked breast tumor growth in a TSLP- and CD4 ${ }^{+} \mathrm{T}$ cell-dependent manner. Endogenous TSLP expressed by breast tumor cells also acted to suppress breast tumor growth. (C) Graph demonstrates the average tumor volumes in 5 cohorts of mice tested ( $n=6$ in each group; ${ }^{*} P<0.05$ compared with the WT plus EtOH group, Student's $t$ test). (D) Representative images of the implanted primary breast tumors are shown (red arrow points to small tumors). Scale bar: $1 \mathrm{~cm}$. (E) CD4 ${ }^{+}$ T cells in calcipotriol-treated WT mice and WT CD4 ${ }^{+} T$ cells transferred into calcipotriol-treated $\mathrm{Ts}_{\mathrm{Ipr}} \mathrm{r}^{-1}$ mice were polarized to Th2 cells. Representative flow cytometric plots of tumor-infiltrating $\mathrm{CD} 4^{+} \mathrm{T}$ cells in recipient mice are shown (numbers in each box represent the percentage of $\mathrm{CD}^{+}$ T cells). Congenically marked (CD45.1 $1^{+}$) WT CD4 ${ }^{+}$T cells are highlighted in red. Bar graph shows the percentage of Th1 and Th2 cells and Tregs within the breast tumors in each group ( $n=6$ per group; ${ }^{*} P<0.05$ compared with the WT plus EtOH group, Student's $t$ test). The data were reproduced in 3 independent experiments. 

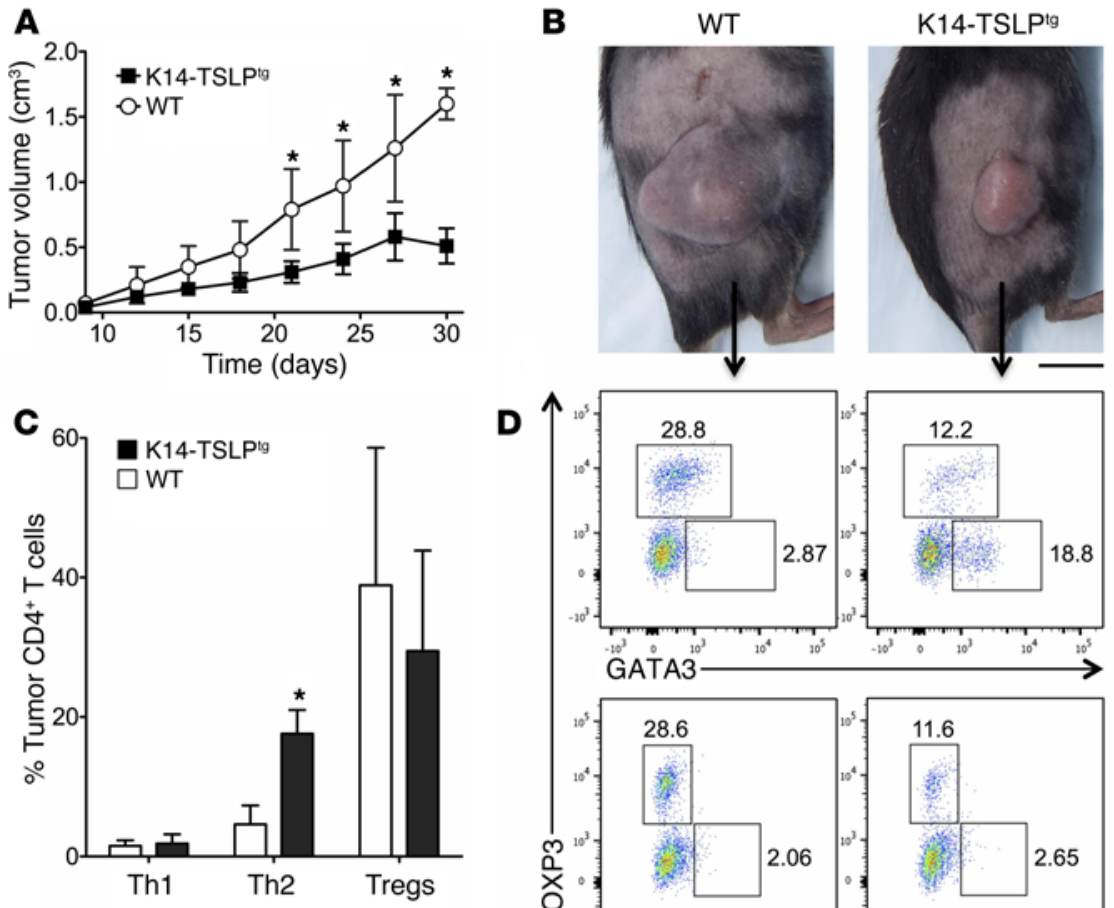

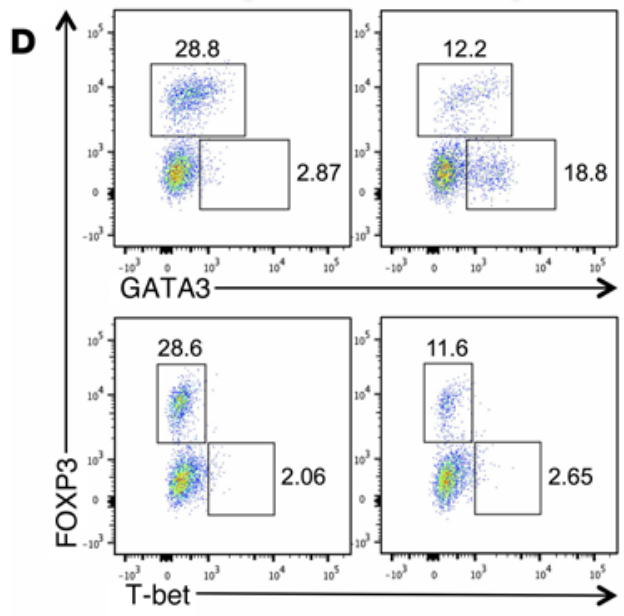

Figure 8. TSLP suppresses primary pancreatic tumor growth. (A) Graph shows the average volume of $P 48^{+/ / \text {re }}$ LSL-KRAS ${ }^{\mathrm{G} 120} p 53^{f / /+}$ pancreatic tumors transferred into WT and K14-TSLPts mice over time. (B) Representative images show tumors 30 days after implantation of primary pancreatic tumor cells into the right flank of 6- to 8-week-old WT and K14-TSLPtg mice. Scale bar: $1 \mathrm{~cm}$. (C) Bar graph shows the percentage of T-bet ${ }^{+}$Th1 cells, GATA3 ${ }^{+}$Th 2 cells, and $\mathrm{FOXP3}^{+}$Tregs in the pancreatic tumors formed in WT and K14-TSLPts animals. (D) Representative flow cytometric plots demonstrate FOXP3, GATA3, and T-bet expression in tumor-infiltrating $C D 4^{+} \mathrm{T}$ cells in recipient mice. The data were reproduced in 2 independent experiments ( $n=6$ in each group; ${ }^{*} P<0.05$ compared with WT, Student's $t$ test). Detailed experimental procedures are available in the Supplemental material. prevent the development of late-stage metastatic cancers, and result in the recruitment of a much broader repertoire of immune effector cells against early and late cancers.

Here, we demonstrate that TSLP-stimulated $\mathrm{CD} 4^{+} \mathrm{Th} 2$ cells are the key mediators of the antitumor immune response that blocks early stages of breast cancer development, protecting animals from advanced breast cancer and metastasis. Importantly, we found that a similar TSLP-induced immunity blocked the growth of primary pancreatic tumors. These findings identify several fundamental concepts that can advance our understanding of immune system interactions with cancer. First, our data suggest that, in addition to $\mathrm{CD}^{+}$CTLs, which are the prime immune cell type studied in cancer immunology (1), CD $4^{+}$Th cells are important players in antitumor immunity, especially in early cancers. This finding suggests that CD8 ${ }^{+}$CTLs found in late-stage cancers may have been initially recruited by $\mathrm{CD} 4^{+}$Th cells responding to the cancer at its earlier stages of development, similar to the initiating role that $\mathrm{CD} 4^{+} \mathrm{T}$ cells play in other inflammatory conditions like autoimmune diabetes (31). Next, this work emphasizes the importance of actively stimulating $\mathrm{CD} 4^{+}$Th cells against early stages of solid cancers like breast cancer, in which baseline antitumor immunity is minimal (3). Through this approach, tumorinfiltrating $\mathrm{CD}^{+} \mathrm{T}$ cells, which are the upstream activators of the immune response, can mediate potent anticancer effects. The $\mathrm{CD}^{+} \mathrm{T}$ cells appeared not to be cytotoxic themselves and did not express tumor-promoting factors; rather, they recruited a broad repertoire of immune effector cells to attack the cancer more effectively. However, the observed effects appear to be independent of mast cells or basophils, since they were found in low densities and were not expanded upon TSLP exposure in the breast cancer lesions. Thus, Th2-polarized lymphocytes are at the heart of the antitumor immune response in the breast, which signifies the previously unrecognized efficacy of this immune cell type in suppressing cancer development.

Although the tumor-protective effects of atopy against skin cancer have been previously described $(7-9,32)$, this study provides clear evidence for a similar effect against an internal cancer with metastatic potential. TSLP is a master regulator of atopic diseases in barrier organs like the skin and lungs (33). In response to barrier disruption, TSLP is expressed by epithelial cells that are attempting to repair the barrier and alert the immune system of the breach. However, in the face of chronic barrier defects, continuous TSLP overexpression leads to the development of atopic dermatitis and asthma in the skin and lungs, respectively (33). Previous reports demonstrated that TSLP-induced allergic inflammation in the skin protected it from cancer (7-9); however, it was not clear whether this protection would extend to cancers in nonbarrier sites. We believe our current findings conclusively demonstrate that systemic TSLP released by the skin mounts an effective antitumor immune response specifically at the site of a developing cancer in the breast and does not cause inflammation in a breast free of initiated cancer cells. Therefore, a barrier organ site for the tumor and preexisting allergic inflammation are not required for TSLP-mediated tumor immunity.

As TSLP is increased in the blood of patients with atopic diseases (18), our results provide an explanation for the reduced rate of cancer in these patients reported in epidemiological studies (15-17). In addition, our calcipotriol studies demonstrate that a short-term induction of systemic TSLP leads to antitumor immunity at the sites of breast cancer development, without generalized allergic inflammation as side effects. Hence, the systemic approach to TSLP induction may provide a safe and effective 
immunotherapy to direct the antitumor immunity specifically to the site of the primary cancer and its micrometastasis.

Importantly, we found that in breast cancer-derived cell lines, the endogenous TSLP signal is coopted by the cancer cells to promote their growth, as shown in previous studies $(10,28)$. This protumorigenic effect of TSLP on breast cancer cell lines is mediated through $\mathrm{OX}_{4} \mathrm{OL}^{+} \mathrm{DCs}(10)$ and may involve a collection of immune cells like the M2 macrophages present in a type 2 inflammatory microenvironment (34). Interestingly, systemic TSLP overexpression can still stimulate the specific expansion of $\mathrm{CD} 4^{+} \mathrm{T}$ cells in the cell line-derived breast tumor and block its growth. Collectively, these results emphasize the importance of TSLP as a potent antitumor immune signal that can be deployed to achieve an effective immunity against early- and late-stage breast cancer.

An important and direct implication of TSLP induction for breast cancer immunotherapy relates to the treatment of lobular and ductal carcinoma in situ (LCIS and DCIS). These localized breast lesions have high rates of recurrence, even after surgical excision $(35,36)$. More important, the presence of a subset of these precancerous lesions is a marker for increased risk of cancer in both breasts $(35,36)$. Importantly and consistent with our findings in animal models, a clinical study recently found that TSLP expression in early-stage breast cancers correlates with improved outcomes (37). Therefore, TSLP induction can prove to be an effective cancer immunotherapeutic against these early breast cancer lesions by directing the adaptive immunity to sites of existing but subclinical cancers and preventing new lesions from developing over time through the immune memory response.

TSLP establishes its tumor immunity against breast cancer by stimulating $\mathrm{CD}^{+} \mathrm{T}$ cells to infiltrate the breast cancer as activated and/or memory Th2 cells. Although we have shown that TSLP-stimulated $\mathrm{CD}^{+}{ }^{+} \mathrm{T}$ cells accumulate in close proximity to $\mathrm{MHCII}^{+}$APCs that have also infiltrated the tumor under TSLP pressure, the exact nature of the antigens that are detected by these $\mathrm{T}$ cells remains to be elucidated in future studies. Also, the effector mechanism of the TSLP-stimulated Th2 cells that effectively blocks breast cancer development remains a topic for future research. We did not find that the tumor-infiltrating $\mathrm{CD} 4^{+} \mathrm{T}$ cells express granzymes, perforin, or Fas ligand, which would give rise to cytotoxic potential. Therefore, other adaptive immune cells like B cells (32) and CD8 ${ }^{+}$CTLs, as well as innate immune cells and/or stromal components of the tumor, are likely playing an effector role downstream of the $\mathrm{CD} 4^{+} \mathrm{T}$ cells to execute the antitumor effects observed.

In summary, this work describes previously unrecognized effects of TSLP and Th2 cells in blocking breast carcinogenesis that can be extended to other cancers, such as pancreatic cancer. TSLP overexpression in the skin establishes a potent antitumor immunity in the breast through direct stimulation of CD4 ${ }^{+} \mathrm{Th} 2$ cells. Likewise, endogenous TSLP released by breast cancer cells suppresses the growth of the cancer, which is later used by breast cancer-derived cell lines to promote their own growth. Together, these findings demonstrate the importance of studying cancer immunology in the context of a developing spontaneous cancer in order to determine the full breadth of immune system interactions with cancer. This study has clear therapeutic implications for the treatment of early and late cancers by providing a mechanism to engage the $\mathrm{CD} 4^{+} \mathrm{T}$ cells to attack the cancer. More specifically, the efficacy of topical calcipotriol in inhibiting breast cancer growth in a TSLP- and Th2 cell-dependent manner provides an exciting possibility for the use of this FDA-approved medication in the treatment of early breast cancer lesions, especially those that are not cured by surgical excision alone.

\section{Methods}

Mice. Mice carrying both K14-TSLP ${ }^{\mathrm{tg}}$ (a gift of Andrew Farr, University of Washington, Seattle, Washington, USA) and PyMt transgenes were generated by crossing PyMt ${ }^{\mathrm{tg}}$ mice on an FVB background with K14-TSLP ${ }^{\text {tg }}$ mice on a mixed background. These K14-TSLP ${ }^{\text {tg }}$ PyMt $^{\text {tg }}$ mice were maintained on an FVB background. For experiments using mice on the $\mathrm{C} 57 \mathrm{BL} / 6$ background, $\mathrm{PyM} \mathrm{t}^{\mathrm{tg}}$ mice generated directly on a C57BL/6 background were crossed with K14-TSLP ${ }^{\text {tg }}$ Tslpr-- mice (Tslpr/- mice were a gift of Warren Leonard, NIH, Bethesda, Maryland, USA) that were also generated directly on a C57BL/6 background. All mice included in the breast cancer experiments were monitored daily for tumor onset and growth. For all breast cancer experiments, the mice were sacrificed if their tumor exceeded $2 \mathrm{~cm}$ in diameter or the animals showed any sign of distress or weight loss. In cancer survival experiments, we harvested one K14-TSLP ${ }^{\mathrm{tg}}$ PyMtg animal, together with any of its end-stage cancer-bearing PyMt littermates, in order to perform our tissue and immune cell analyses on the test and control mice at the same age; hence, some of the K14-TSLP ${ }^{\mathrm{tg}}$ PyMttg animals that were otherwise healthy exited the survival analysis at the time of euthanasia.

$A b$ depletion. $\mathrm{K}_{14}-\mathrm{TSLP}^{\mathrm{tg}} \mathrm{PyMt}^{\mathrm{tg}}$ and $\mathrm{PyMt}^{\mathrm{tg}}$ mice received an i.p. injection of $750 \mu \mathrm{g}$ anti-CD4 (GK1.5) and/or anti-CD8 (YTS169.4) or control Ab (anti-rat IgG; Sigma-Aldrich) in the second week of life. The animals continued to receive $250 \mu$ g depleting Abs weekly. AntiCD4 and anti-CD8 Abs were produced by the Protein Production and Purification Facility of the Rheumatic Diseases Core Center (RDCC) at Washington University.

Primary breast tumor transfer and calcipotriol treatment studies. Primary breast tumor cells were obtained from PyMt ${ }^{\mathrm{tg}}$ or PyMt ${ }^{\mathrm{tg}} \mathrm{Tslpr}^{--}$ donor mice. Primary tumors in the donor animals were harvested before the tumors reached $2 \mathrm{~cm}$ in diameter. Donor mice were injected with $50 \mu \mathrm{l}$ heparin, followed by anesthetics and whole-body perfusion with $30 \mathrm{ml}$ PBS under sterile conditions. Approximately 3 to 4 grams of whole tumor was then meshed through a 70- $\mu$ m filter into a lysing solution consisting of RPMI (Sigma-Aldrich), Liberase TL $(170 \mu \mathrm{g} /$ $\mathrm{ml}$; Roche), and DNase I (30 $\mu \mathrm{g} / \mathrm{ml}$; Roche) in a 6-well plate. A breast tumor single-cell suspension and small pieces were transferred into a $50-\mathrm{ml}$ tube and placed in a shaker at $37^{\circ} \mathrm{C}$ for 2 hours at $225 \mathrm{rpm}$. A breast tumor single-cell suspension was then meshed through a new $70-\mu \mathrm{m}$ filter into a fresh $50-\mathrm{ml}$ tube. Breast tumor cells were resuspended in $2 \mathrm{ml}$ MACS buffer (0.5\% BSA and $2 \mathrm{mM}$ EDTA in PBS), followed by $100 \mu \mathrm{l} \mathrm{CD} 45^{+}$microbeads for 30 minutes on ice (Miltenyi Biotec). Primary breast tumor cells were isolated away from CD $45^{+}$ leukocytes using $\mathrm{CD} 45^{+}$microbeads and magnetic columns according to the manufacturer's protocol (Miltenyi Biotec). Primary breast tumor cells were resuspended at a concentration of $2 \times 10^{6}$ cells per $200 \mu \mathrm{l}$ RPMI (Sigma-Aldrich). Cells $\left(2 \times 10^{6} /\right.$ mouse) were injected into the animals' right inguinal mammary fat pad (ninth mammary gland) on day 0 (D0). For adoptive $\mathrm{T}$ cell transfer experiments, CD4 ${ }^{+} \mathrm{T}$ cells were injected 2 days before tumor implantation. In topical calcipotriol treatment experiments, the mice were divided into 2 groups and were 
treated with either calcipotriol $(20 \mathrm{nmol})$ or ethanol as a carrier on their ears starting 2 days before $\mathrm{CD}^{+} \mathrm{T}$ cell transfer. Calcipotriol or ethanol treatments were continued every 3 days.

Breast cancer cell line studies. The PyMt ${ }^{\mathrm{tg}}$ cancer cell line was generated from a mammary tumor from a 6-month-old PyMt ${ }^{\mathrm{tg}}$ mouse on a C57BL/6 background. Tumor cells were grown on collagen-coated plates in $10 \%$ FBS plus DMEM and passaged 10 times before use. The cell line was screened for vimentin and EpCAM to verify its epithelial nature. Cells were screened for mouse Ab production (MAP) and mycoplasma. Cells were passaged at $70 \%$ confluency, and $4 \times 10^{5}$ breast cancer cells were injected into the lateral inguinal mammary fat pad (ninth mammary gland) on DO.

Statistics. All statistical analyses for tumor onset and survival were performed using the log-rank test to determine significant differences between study groups in 2-way comparisons with the control group. A 2-tailed Student's $t$ test was used to determine significance between tumor counts, tumor volumes, mRNA expression, TSLP serum levels, and all other measurements in 2-way comparisons with the control group. A $P$ value of less than 0.05 was considered significant, and all error bars represent SD.

Study approval. All mice were maintained in pathogen-free facilities according to guidelines instituted by the animal study committees of Washington University and Massachusetts General Hospital. All animal studies were reviewed and approved by the IACUCs of Washington University and Massachusetts General Hospital.

Refer to the Supplemental Methods for further description of the experimental procedures.

\section{Author contributions}

SD conceived and designed the experiments. SD, TJC, SM, KHN, SMT, and RR performed the experiments and analyzed the data. SD and WMY interpreted the data and wrote the manuscript. MAM and DGD contributed experimental reagents and data.

\section{Acknowledgments}

We thank the Yokoyama and DeNardo laboratory members Emil R. Unanue and Herbert W. Virgin for their critical reading of the manuscript. We thank Andrew Farr for the K14-TSLP ${ }^{\text {tg }}$ mice, Warren Leonard for the Tslpr/- mice, and Raphael Kopan and Ahu Turkoz for their assistance with the early generation of the animal models used in this study (NIH RO1 CA163353 and NIH P50 CA094056-07, to R. Kopan). We thank the Washington University Digestive Diseases Research Core Center (NIH grant P3ODK052574) for assistance with IHC studies and the Washington University Rheumatic Diseases Core Center (NIH grant P03AR048335) for the Abs used in the depletion studies. The NanoZoomer imaging facility is supported by NIH Shared Instrumentation grant S10-RR0227552. W.M. Yokoyama is an Investigator of the Howard Hughes Medical Institute. S. Demehri is supported by grants from the American Skin Association, the Dermatology Foundation, and the NIH (1DP5OD021353).

Address correspondence to: Shadmehr Demehri, Building 149 13th Street, 3rd floor, Charlestown, Massachusetts 02129, USA. Phone: 617.643.6436; E-mail: sdemehri1@mgh.harvard.edu.
1. Mellman I, Coukos G, Dranoff G. Cancer immunotherapy comes of age. Nature. 2011;480(7378):480-489.

2. Criscitiello C, Curigliano G. Immunotherapeutics for breast cancer. Curr Opin Oncol. 2013;25(6):602-608.

3. Clark CE, Hingorani SR, Mick R, Combs C, Tuveson DA, Vonderheide RH. Dynamics of the immune reaction to pancreatic cancer from inception to invasion. Cancer Res. 2007;67(19):9518-9527.

4. Pardoll DM. The blockade of immune checkpoints in cancer immunotherapy. Nat Rev Cancer. 2012;12(4):252-264.

5. Lo Kuan E, Ziegler SF. Thymic stromal lymphopoietin and cancer. J Immunol. 2014;193(9):4283-4288.

6. Ziegler SF. Thymic stromal lymphopoietin and allergic disease. J Allergy Clin Immunol. 2012;130(4):845-852.

7. Demehri S, Turkoz A, Manivasagam S, Yockey LJ, Turkoz M, Kopan R. Elevated epidermal thymic stromal lymphopoietin levels establish an antitumor environment in the skin. Cancer Cell. 2012;22(4):494-505.

8. Di Piazza M, Nowell CS, Koch U, Durham AD, Radtke F. Loss of cutaneous TSLP-dependent immune responses skews the balance of inflammation from tumor protective to tumor promoting. Cancer Cell. 2012;22(4):479-493.

9. Cipolat S, Hoste E, Natsuga K, Quist SR, Watt FM. Epidermal barrier defects link atopic dermatitis with altered skin cancer susceptibility. Elife. 2014;3:e01888.
10. Pedroza-Gonzalez A, et al. Thymic stromal lymphopoietin fosters human breast tumor growth by promoting type 2 inflammation. J Exp Med. 2011;208(3):479-490.

11. Li M, Hener P, Zhang Z, Kato S, Metzger D, Chambon P. Topical vitamin D3 and low-calcemic analogs induce thymic stromal lymphopoietin in mouse keratinocytes and trigger an atopic dermatitis. Proc Natl Acad Sci US A. 2006;103(31):11736-11741.

12. Sato-Deguchi E, Imafuku S, Chou B, Ishii K, Hiromatsu K, Nakayama J. Topical vitamin D(3) analogues induce thymic stromal lymphopoietin and cathelicidin in psoriatic skin lesions. Br J Dermatol. 2012;167(1):77-84.

13. Demehri S, Morimoto M, Holtzman MJ, Kopan R. Skin-derived TSLP triggers progression from epidermal-barrier defects to asthma. PLoS Biol. 2009;7(5):e1000067.

14. Zhang Z, et al. Thymic stromal lymphopoietin overproduced by keratinocytes in mouse skin aggravates experimental asthma. Proc Natl Acad Sci US A. 2009;106(5):1536-1541.

15. Vena JE, Bona JR, Byers TE, Middleton E Jr, Swanson MK, Graham S. Allergy-related diseases and cancer: an inverse association. Am JEpidemiol. 1985;122(1):66-74.

16. Hedderson MM, Malone KE, Daling JR, White E. Allergy and risk of breast cancer among young women (United States). Cancer Causes Control. 2003;14(7):619-626.

17. Wang H, Diepgen TL. Is atopy a protective or a risk factor for cancer? A review of epidemiological studies. Allergy. 2005;60(9):1098-1111.
18. Lee EB, Kim KW, Hong JY, Jee HM, Sohn MH, Kim KE. Increased serum thymic stromal lymphopoietin in children with atopic dermatitis. Pediatr Allergy Immunol. 2010;21(2 pt 2):e457-e460.

19. Vargo-Gogola T, Rosen JM. Modelling breast cancer: one size does not fit all. Nat Rev Cancer. 2007;7(9):659-672.

20. Demehri S, et al. Notch-deficient skin induces a lethal systemic B-lymphoproliferative disorder by secreting TSLP, a sentinel for epidermal integrity. PLoS Biol. 2008;6(5):e123.

21. Tarulli GA, et al. Hormone-sensing cells require Wip1 for paracrine stimulation in normal and premalignant mammary epithelium. Breast Cancer Res. 2013;15(1):R10.

22. Osuala KO, et al. Il-6 signaling between ductal carcinoma in situ cells and carcinoma-associated fibroblasts mediates tumor cell growth and migration. BMC Cancer. 2015;15:584.

23. Singh JK, Simoes BM, Howell SJ, Farnie G, Clarke RB. Recent advances reveal IL-8 signaling as a potential key to targeting breast cancer stem cells. Breast Cancer Res. 2013;15(4):210.

24. Kim BS, et al. TSLP elicits IL-33-independent innate lymphoid cell responses to promote skin inflammation. Sci Transl Med. 2013;5(170):170ra116.

25. Kitajima M, Ziegler SF. Cutting edge: identification of the thymic stromal lymphopoietinresponsive dendritic cell subset critical for initiation of type 2 contact hypersensitivity. J Immunol. 2013;191(10):4903-4907.

26. Engelhardt JJ, et al. Marginating dendritic cells of the tumor microenvironment cross-present 


\section{RESEARCH ARTICLE}

tumor antigens and stably engage tumor-specific T cells. Cancer Cell. 2012;21(3):402-417.

27. DeNardo DG, et al. CD4(+) T cells regulate pulmonary metastasis of mammary carcinomas by enhancing protumor properties of macrophages. Cancer Cell. 2009;16(2):91-102.

28. Olkhanud PB, et al. Thymic stromal lymphopoietin is a key mediator of breast cancer progression. J Immunol. 2011;186(10):5656-5662.

29. De Monte L, et al. Intratumor T helper type 2 cell infiltrate correlates with cancer-associated fibroblast thymic stromal lymphopoietin production and reduced survival in pancreatic cancer. JExp Med. 2011;208(3):469-478.
30. Hingorani SR, et al. Preinvasive and invasive ductal pancreatic cancer and its early detection in the mouse. Cancer Cell. 2003;4(6):437-450.

31. Calderon B, Carrero JA, Unanue ER. The central role of antigen presentation in islets of Langerhans in autoimmune diabetes. Curr Opin Immunol. 2014;26:32-40.

32. Strid J, Sobolev O, Zafirova B, Polic B, Hayday A. The intraepithelial $\mathrm{T}$ cell response to NKG2Dligands links lymphoid stress surveillance to atopy. Science. 2011;334(6060):1293-1297.

33. Ziegler SF, Artis D. Sensing the outside world: TSLP regulates barrier immunity. Nat Immunol. 2010;11(4):289-293.
34. Johansson M, Denardo DG, Coussens LM. Polarized immune responses differentially regulate cancer development. Immunol Rev. 2008;222:145-154.

35. Masannat YA, Bains SK, Pinder SE, Purushotham AD. Challenges in the management of pleomorphic lobular carcinoma in situ of the breast. Breast. 2013;22(2):194-196.

36. Schnitt SJ. Local outcomes in ductal carcinoma in situ based on patient and tumor characteristics. J Natl Cancer Inst Monogr. 2010;2010(41):158-161.

37. Yu H, Yang J, Li Y, Jiao S. [The expression of thymic stromal lymphopoietin in primary tumors of breast cancer is associated with prognosis]. Xi Bao Yu Fen Zi Mian Yi Xue Za Zhi. 2015;31(2):239-243. 